\title{
Magnetic-Doublet Theory in the
}

Analysis of Total-Intensity

\section{Anomalies}

GEOLOGICAL SURVEY BULLETIN 1052 -D

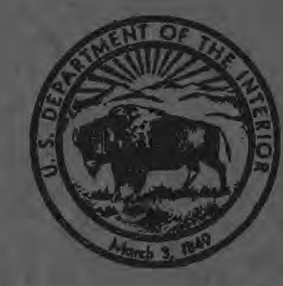




\section{Magnetic-Doublet Theory in the}

Analysis of Total-Intensity

\section{Anomalies}

By ROLAND G. HENDERSON and ISIDORE ZIETZ

EXPERIMENTAL AND THEORETICAL GEOPHYSICS

GEOLOGICAL SURVEY BULLETIN $1052-$ D

Discusses typical magnetic-doublet profiles and their use in the interpretation of aeromagnetic maps

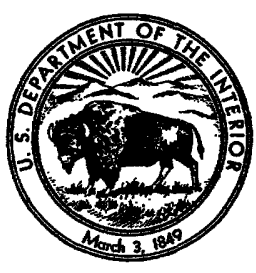




\section{UNITED STATES DEPARTMENT OF THE INTERIOR}

FRED A. SEATON, Secretary

GEOLOGIGAL SURVEY

Thomas B. Nolan, Director 


\section{CONTENTS}

Limitations of magnetic interpretations...................... 159

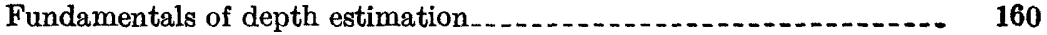

Purpose and scope of investigation

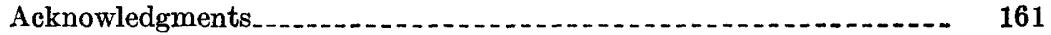

Theoretical doublet anomalies_._. . . . .

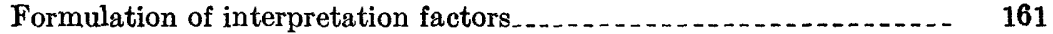

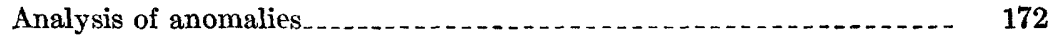

Other uses of computed anomalies............................ 173

Magnetic model experiments._.

Tests on cylindrical models.............. 174

Magnetic double-layer models............................ 176

Practical applications............ 179

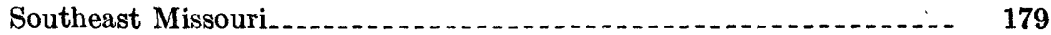

Indiana .................... 181

Ontario, Canada........... 183

Adirondack Mountains, N. Y

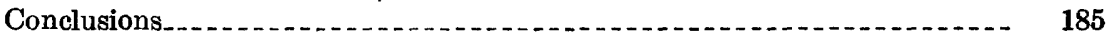

Literature cited....... 185

\section{ILLUSTRATIONS}

FIguRE 27. Total-intensity anomaly of inclined doublet; coordinate system and meaning of $\beta$ and $\delta$

28. Total-intensity anomalies of magnetic doublet of length, $l=0.01$ depth unit. . . . . . . . . . . .

29. Total-intensity anomalies of magnetic doublet of length,

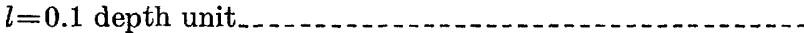

30. Total-intensity anomalies of magnetic doublet of length,

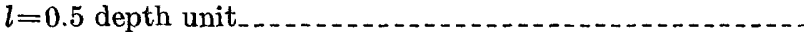

31. Total-intensity anomalies of magnetic doublet of length,

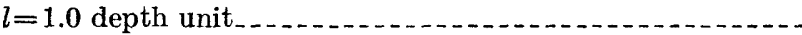

32. Total-intensity anomalies of magnetic doublet of length,

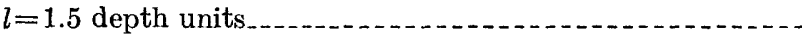

33. Total-intensity anomalies of magnetic doublet of length,

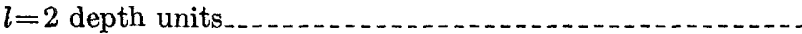

34. Total-intensity anomalies of magnetic doublet of length,

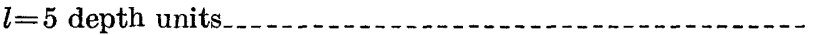

35. Total-intensity anomalies of doublets showing effect of increasing length, $l_{\ldots} \ldots$

36. Total-intensity anomaly of inclined cylinder; obtained from

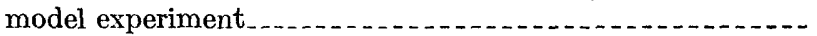


FraURE_37. Total-jntensity anomaly of magnetized plate; obtained from

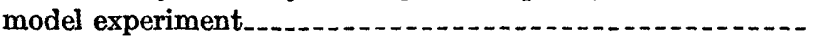

38. Anomalies of inclined cylinders showing effect of increasing diameter

39. Total-intensity aeromagnetic map of part of Coldwater quadrangle, Missouri.

40. Total-intensity aeromagnetic map of area near Bryant, Jay County, Ind

41. Total-intensity aeromagnetic map of T. 34 N., R. 3 W., La Porte County, Ind

42. Total-intensity aeromagnetic map of area near Marmora, Ontario, Canada.

43. Total-intensity aeromagnetic map of northern part of Stark quadrangle, New York

\section{TABLES}

TABLE 1. Comparison of numerical values for two different definitions of $\boldsymbol{\beta}$

2. Parameters of magnetic doublets for inclinations, $I$, and length-to-depth ratios, $l / d \ldots$

3. Comparison of calculated doublet lengths and depths with

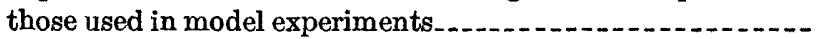

4. Application of magnetic-doublet theory to field of hori-

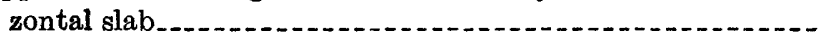




\title{
EXPERIMENTAL AND THEORETICAL GEOPHYSICS
}

\section{MAGNETIC-DOUBLET THEORY IN THE ANALYSIS OF TOTAL-INTENSITY ANOMALIES}

\author{
By Roland G. Henderson and Istdore Zietz
}

\begin{abstract}
Analysis of horizontal- or vertical-intensity magnetic anomalies in terms of equivalent magnetic doublets has been extensively used for rough estimates of depth and depth extent of disturbing rocks. In this investigation, factors have been theoretically determined by which appropriate total-intensity anomalies can also be analyzed in terms of their magnetic-doublet equivalents. The effectiveness and limitations of the method have been checked by application to anomalies derived from model experiments and to observed anomalies. For satisfactory results the effective radius of the disturbing body must be less than its depth of burial. The calculation of doublet length is not so reliable as the calculation of depth; however, the former is better at low magnetic latitudes.
\end{abstract}

\section{INTRODUCTION}

\section{IIMITATIONS OF MAGNETIC INTERPRETATIONS}

The results of aeromagnetic surveys are usually presented in the form of contour maps showing lines of equal total magnetic intensity. The anomalies of interest to exploration geophysicists are departures from smooth regularity, for they are indicative of inhomogeneities in the magnetism of the earth's crust. The relation of anomalies to subsurface geologic structure and to ore bodies is usually uncertain. For this reason interpretations of magnetic anomalies are often qualitative in nature, the map being discussed in terms of "grain" of the anomalies and generalization about likely contrasts in magnetic properties of the basement rocks from which the anomalies probably arise. In general, broad magnetic gradients several tens of miles in linear section represent regional variations in magnetization of the crust; anomalies 10 or 20 miles in lateral extent are associated with more abrupt changes in the magnetic character of the basement rocks; and areally small, high-gradient anomalies are indicative of nearsurface concentrations of ferromagnetic materials. 
The quantitative interpretation of aeromagnetic maps is at once a complicated and challenging area of geophysical investigation. The complications stem largely from the presence of induced and permanent (sometimes called remanent) magnetism in the disturbing body, from lack of knowledge of the magnetic and geometric parameters of the body, and from an inherent ambiguity affecting interpretation of potential fields. The ambiguity arises from the fact that there are many distributions of magnetic material at various depths which can produce a given anomaly. Supplementary geological and geophysical information is therefore necessary for unequivocal solutions.

\section{FUNDAMENTALS OF DEPTH ESTIMATION}

Useful estimates of depths to disturbing bodies are often possible from magnetic anomalies despite these limitations. The relative positions of the maximums, minimums, and inflection points of an anomaly (the so-called shape factors) are functions of the depth and are affected only in a limited way by the remaining geometric parameters of the configuration of the body. These characteristic shape factors are unaffected by blockwise lateral changes in magnetic susceptibility of the basement or by the magnitude of the remanent magnetism when the latter is in the direction of the induced magnetism. Most methods of estimating depth are based on quasi-empirical facts deduced from studies of the shape characteristics of theoretical anomalies. Induction theory is used almost exclusively. It is assumed that the magnetization is the product of the susceptibility contrast and the normal field strength, and that the direction of magnetization is that of the normal field.

Since the advent of the airborne magnetometer, there have been several papers on methods of depth analysis. In the method outlined by Vacquier and others (1951), the shape characteristics of an observed field are compared with those of prismatic-model fields, the comparison being facilitated by the use of second derivatives of the anomaly which bring the shape characteristics into sharper focus. The method has been used successfully in depth analyses of many broad, large-amplitude anomalies (Zietz and Henderson, 1956; Henderson and Zietz, 1958).

\section{PURPOSE AND SCOPE OF INVESTIGATION}

Where the breadth of the anomaly is comparable to the depth of the source, the Vacquier method is less effective because the shape characteristics become more sensitive to parameters of the geometry other than the depth. Analyses of such anomalies can be made in terms of equivalent magnetic doublets. By equivalent magnetic doublet we mean two magnetic poles of equal strength and opposite 
sign, whose depths below the surface and mutual displacement in the direction of the earth's normal field are sufficient to account for the shape characteristics of the anomaly. In standard texts on geophysics, such as Heiland (1940), Jakosky (1950), and Nettleton (1940), magnetic doublets are discussed in relation to the anomaly in the vertical component $(\Delta Z)$ and the anomaly in the horizontal component $(\Delta H)$, but no general treatment for depth calculations is given. Vestine and Davids (1945) presented an ingenious method for analyzing $\Delta Z$ in terms of magnetic doublets.

In airborne magnetometry, however, we are interested in the component of the total-intensity anomaly in the direction of the total field vector. It is a linear combination of $\Delta Z$ and $\Delta H$ and existing theory of the interpretation of doublets is not in general applicable. The work reported here was undertaken to establish a set of model anomaly curves for $\Delta T$ doublets and to deduce from them factors that are diagnostic of the doublet parameters. Major interest is centered in the calculation of depth to the upper (or nearer) pole; however, the more intractable problem of doublet length is also considered. There is some latitude in the choice of specific portions of an anomaly profile for formulating the factors. In every case the choice was dictated by considerations of usefulness in practical applications. The method has been tested by application to laboratory magnetic models, and its application to practical anomalies is demonstrated.

\section{ACKNOWLEDGMENTS}

We acknowledge our indebtedness to Mr. L. R. Alldredge, formerly of the Electricity and Magnetism Division of the Physics Research Department of the Naval Ordnance Laboratory, for the use of the magnetic testing equipment, and to Messrs. C. L. Parsons and K. E. Dornstreich, also of the Naval Ordnance Laboratory, for valuable technical assistance.

\section{THEORETICAL DOUBLET ANOMALIES}

\section{FORMULATION OF INTERPRETATION FACTORS}

In this study it is tacitly assumed that the doublet is produced only by induction in the earth's magnetic field, and that the north dip of the doublet is equal to the magnetic inclination. A right-handed system of coordinates is adopted (fig. 27) with origin at $O, x$ positive to magnetic north, $y$ positive to the east, and $z$ positive vertically downwards. The components of the magnetic field, $\Delta X, \Delta Y$, and $\Delta Z$, are positive along the respective coordinate axes. The doublet of strength $m$ and length $l$ lies in the $x z$ plane; the coordinates of the pole nearer the origin are $(0,0, d)$, and those of the remote pole are $(l \cos I, O, d+l \sin I)$. 


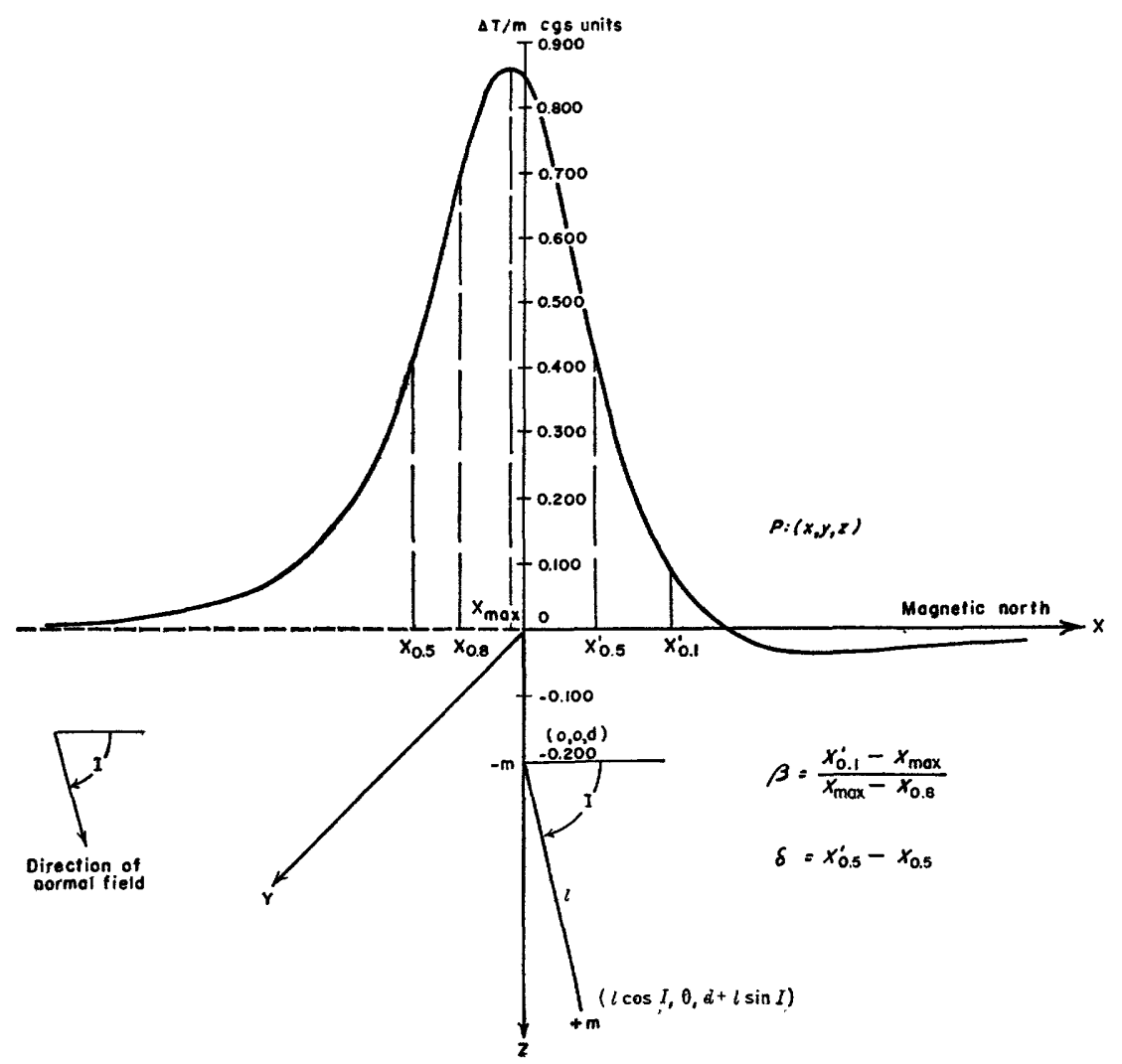

FIGURE 27.-Total-intensity anomaly of inclined doublet; coordinate system and meaning of $\beta$ and $\delta$.

The general expression for the anomaly at any point $P:(x, y, z)$ is given by-

$$
\begin{array}{r}
\Delta T(x, y, z)=m\left\{\frac{(x-l \cos I)}{\left[(l \cos I-x)^{2}+y^{2}+(d+l \sin I-z)^{2}\right]^{3 / 2}}-\right. \\
\left.\frac{x}{\left[x^{2}+y^{2}+(d-z)^{2}\right]^{3 / 2}}\right\} \cos I+m\left\{\frac{(d-z)}{\left[x^{2}+y^{2}+(d-z)^{2}\right]^{3 / 2}}-\right. \\
\left.\frac{(d+l \sin I-z)}{\left[(l \cos I-x)^{2}+y^{2}+(d+l \sin I-z)^{2}\right]^{3 / 2}}\right\} \sin I
\end{array}
$$

where it has been assumed that the magnetic inclination is constant over the area. If $y=z=0$ and $m=1$, and all linear measures are expressed in terms of $d=1$, a profile along the $x$ axis is given by 


$$
\begin{aligned}
\Delta T(x)= & \left\{\frac{(x-l \cos I)}{\left[(l \cos I-x)^{2}+(1+l \sin I)^{2}\right]^{3 / 2}}-\frac{x}{\left[x^{2}+1\right]^{3 / 2}}\right\} \cos I+ \\
& \left\{\frac{1}{\left[x^{2}+1\right]^{3 / 2}}-\frac{1+l \sin I}{\left[(l \cos I-x)^{2}+(1+l \sin I)^{2}\right]^{3 / 2}}\right\} \sin I
\end{aligned}
$$

From formula (1), $\Delta T(x)$ was computed for doublets with parameters $l / d=0.01,0.10,0.50,1.00,1.50,2.00,5.00$; and inclinations, $I=0^{\circ}$, $30^{\circ}, 45^{\circ}, 60^{\circ}, 75^{\circ}, 90^{\circ}$. These are shown in figures 28 to 34 .

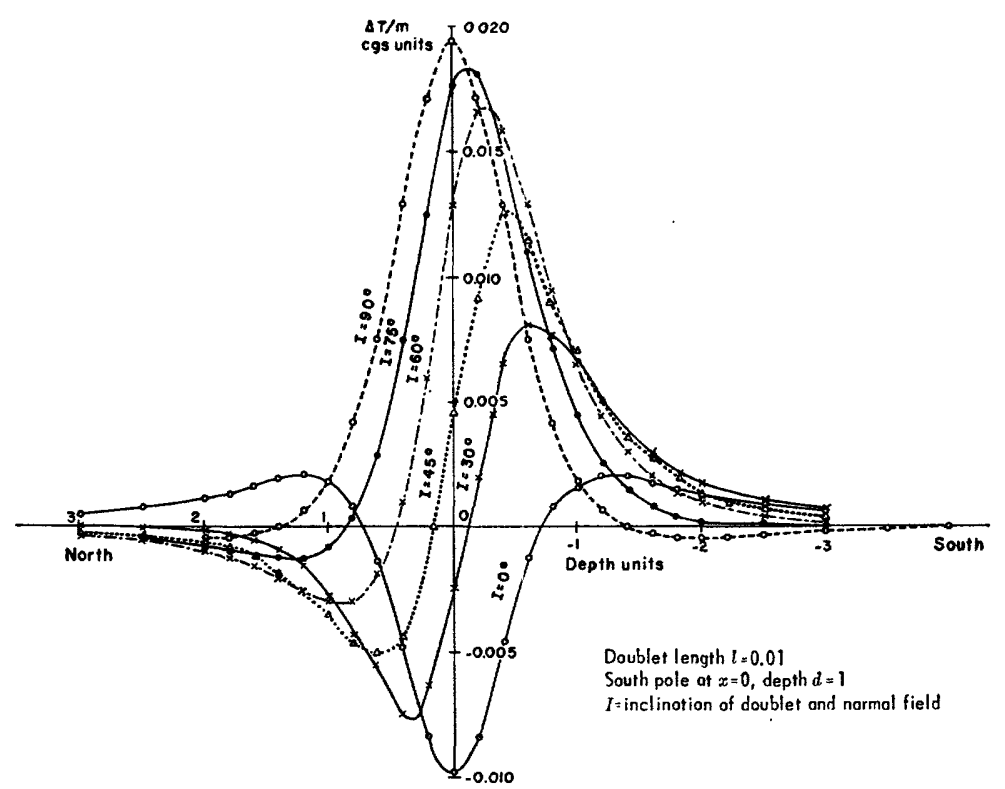

Fioure 28.-Total-intensity anomalies of magnetic doublet of length, $l=0.01$ depth unit.

From an empirical study of theoretical doublet-anomaly curves of this type, it is possible to determine factors, herein designated $\beta$ and $\delta$, which are useful in estimating $l$ and $d$ from observed anomalies. The dimensionless factor $\beta$ involves the ratio between certain horizontal distances subtended by the curve, and $\delta$ is a horizontal distance, usually between half-maximum abscissas or between nearly inflectional points. In figure 27, $\beta=\left(x^{\prime}{ }_{0.1}-x_{\max }\right) /\left(x_{\max }-x_{0.8}\right)$ and $\delta=x_{0.5}^{\prime}-x_{0.5}$ where $x_{\max }, x_{0.1}, x_{0.5}, x_{0.8}$ are the abscissas of $\Delta T_{\max }, 0.1$ $\Delta T_{\max }, 0.5 \Delta T_{\max }$, and $0.8 \Delta T_{\max }$, respectively. Prime marks refer to the more northerly of two points. 


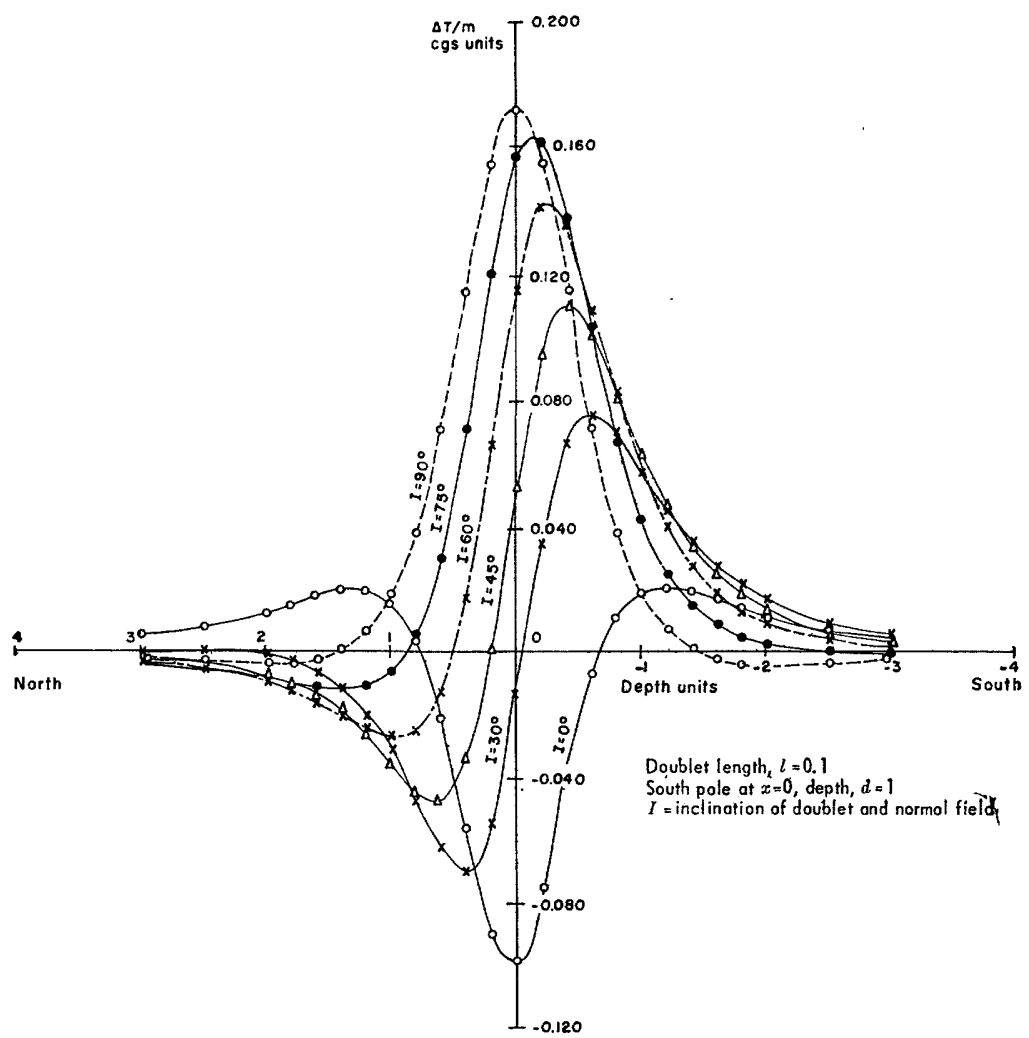

Frgure 29.-Total-intensity anomalies of magnetic doublet of length, $l=0.1$ depth unit.

Practical considerations require that $\beta$ be determined from portions of the curve that are easily identifiable and, at most, only slightly affected by nearby disturbances. Peripheral features should be avoided as far as possible. Moreover, $\beta$ and $\delta$ must be so chosen that there will be resolution between successive values of $l / d$. To satisfy these requirements, $\beta$ and $\delta$ are necessarily different for each inclination. The selection of abscissas is facilitated if the vertical scale of each of the family of $\Delta T(x)$ curves is adjusted so that all maximums have the same amplitude, as is shown in figure 35 for $I=75^{\circ}$. If in this figure, $\beta$ were chosen in two different ways, say $\beta_{1}=\left(x_{0.5}-x_{\max }\right) /$ $\left(x_{\max }-x_{0.5}^{\prime}\right)$ and $\beta_{2}=\left(x_{0.1}^{\prime}-x_{\max }\right) /\left(x_{\max }-x_{0.8}\right)$, the tabulation would be that shown in table 1 . 


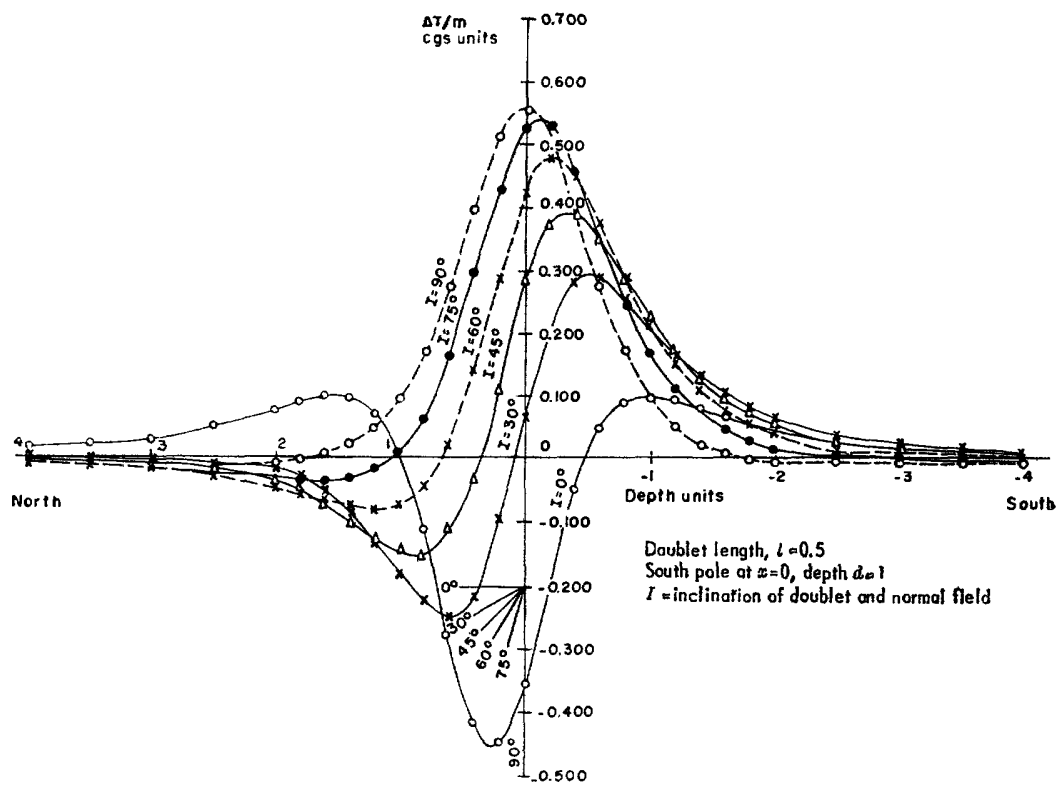

Frodre 30.-Total-intensity anomalies of magnetic doublet of length, $z=0.6$ depth unit.

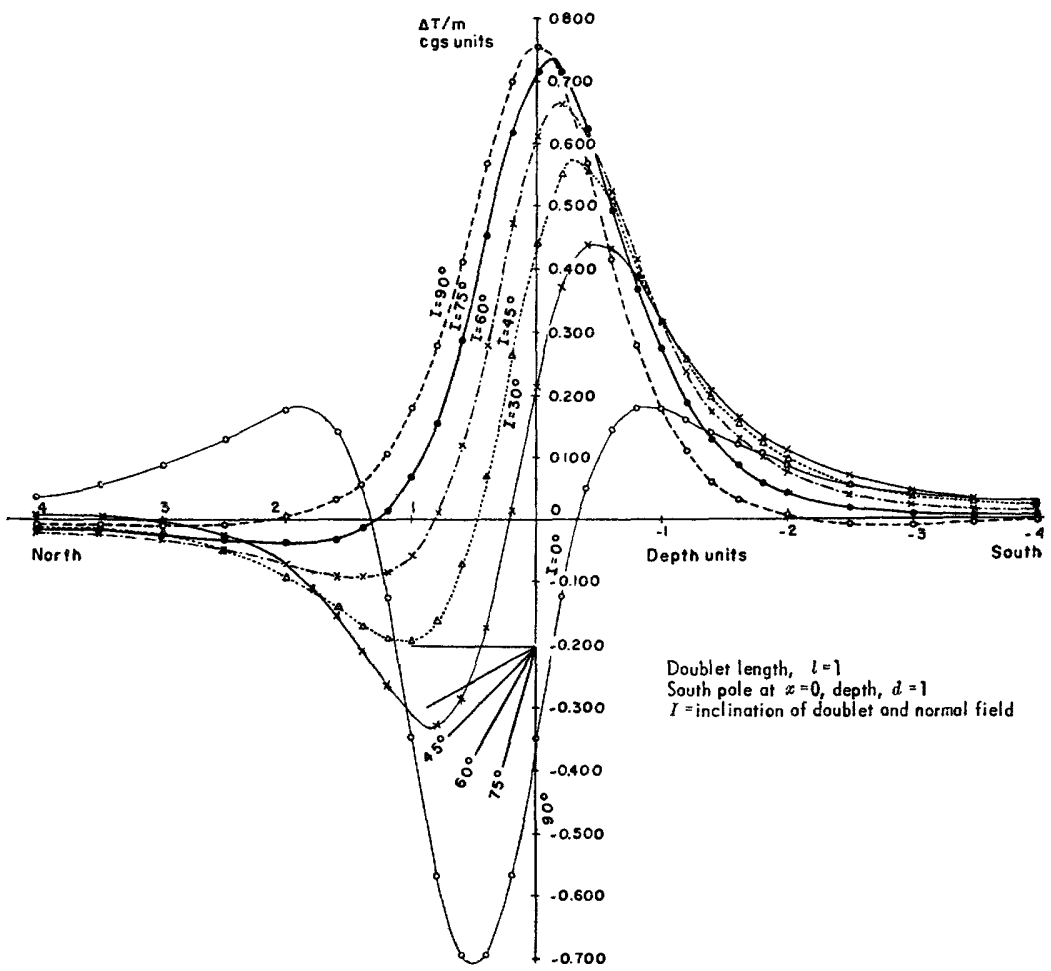

Frgure 31.-Total-mtensity anomalies of magnetic doublet of length, $z=1.0$ depth unit. 


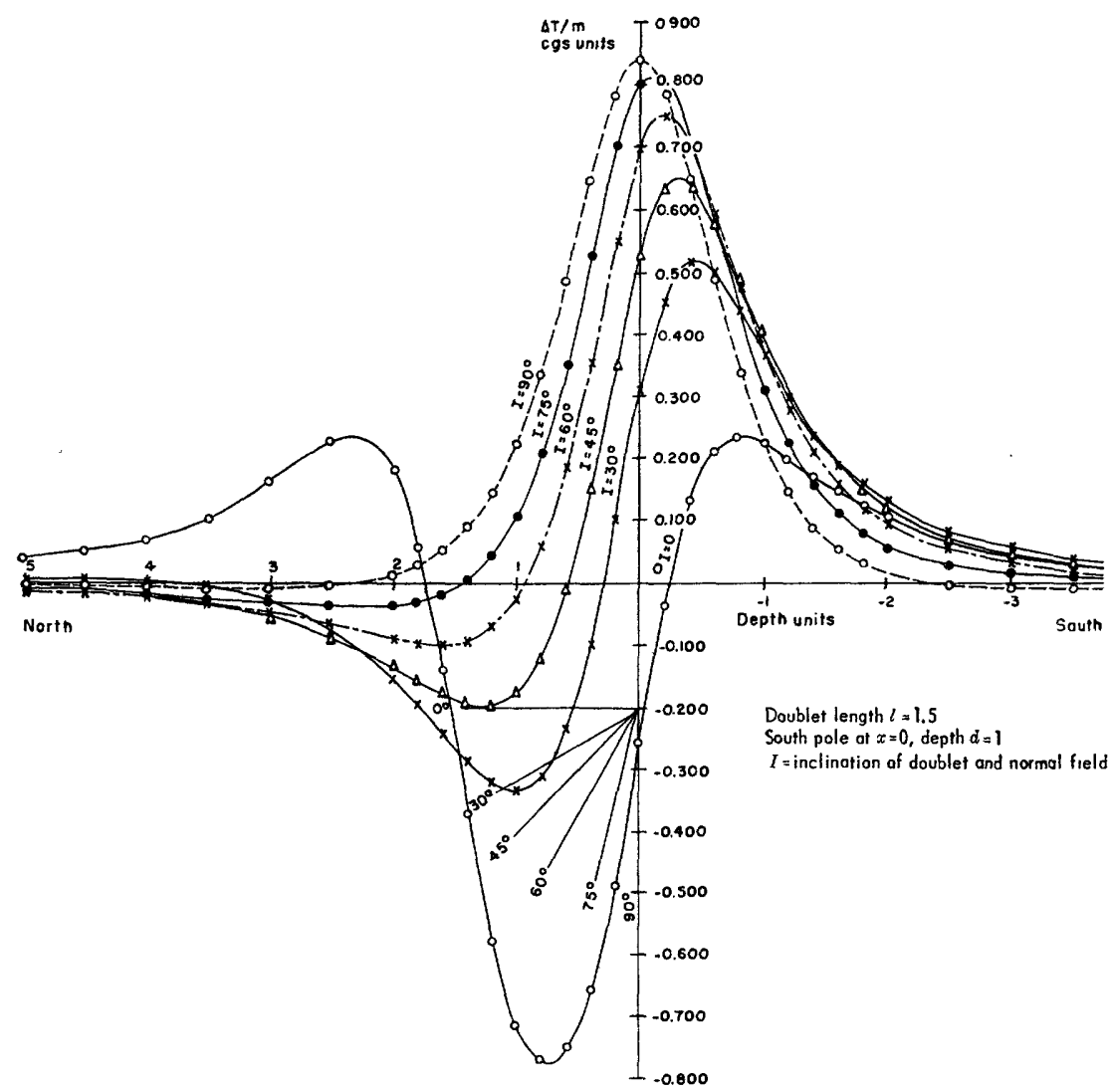

Froore_32.-Total-intensity anomalies of magnetic doublet of length, $l=1.5$ depth units.

TABw 1.-Comparison of numerical values for two different definitions of $\beta$

\begin{tabular}{|c|c|c|c|c|c|c|c|}
\hline$l / d$ & 0.01 & 0.10 & 0.50 & 1.00 & 1.50 & 2.00 & 5.00 \\
\hline $\begin{array}{l}\beta_{1} \ldots \\
\beta_{2} \ldots\end{array}$ & $\begin{array}{l}1.24 \\
2.52\end{array}$ & $\begin{array}{l}1.23 \\
2.68\end{array}$ & $\begin{array}{l}1.22 \\
\text { 2. } 79\end{array}$ & $\begin{array}{l}1.17 \\
3.00\end{array}$ & $\begin{array}{l}\text { 1. } 14 \\
\text { 3. } 19\end{array}$ & $\begin{array}{l}\text { 1. } 12 \\
\text { 3. } 21\end{array}$ & $\begin{array}{l}\text { 1. } 08 \\
\text { 3. } 59\end{array}$ \\
\hline
\end{tabular}




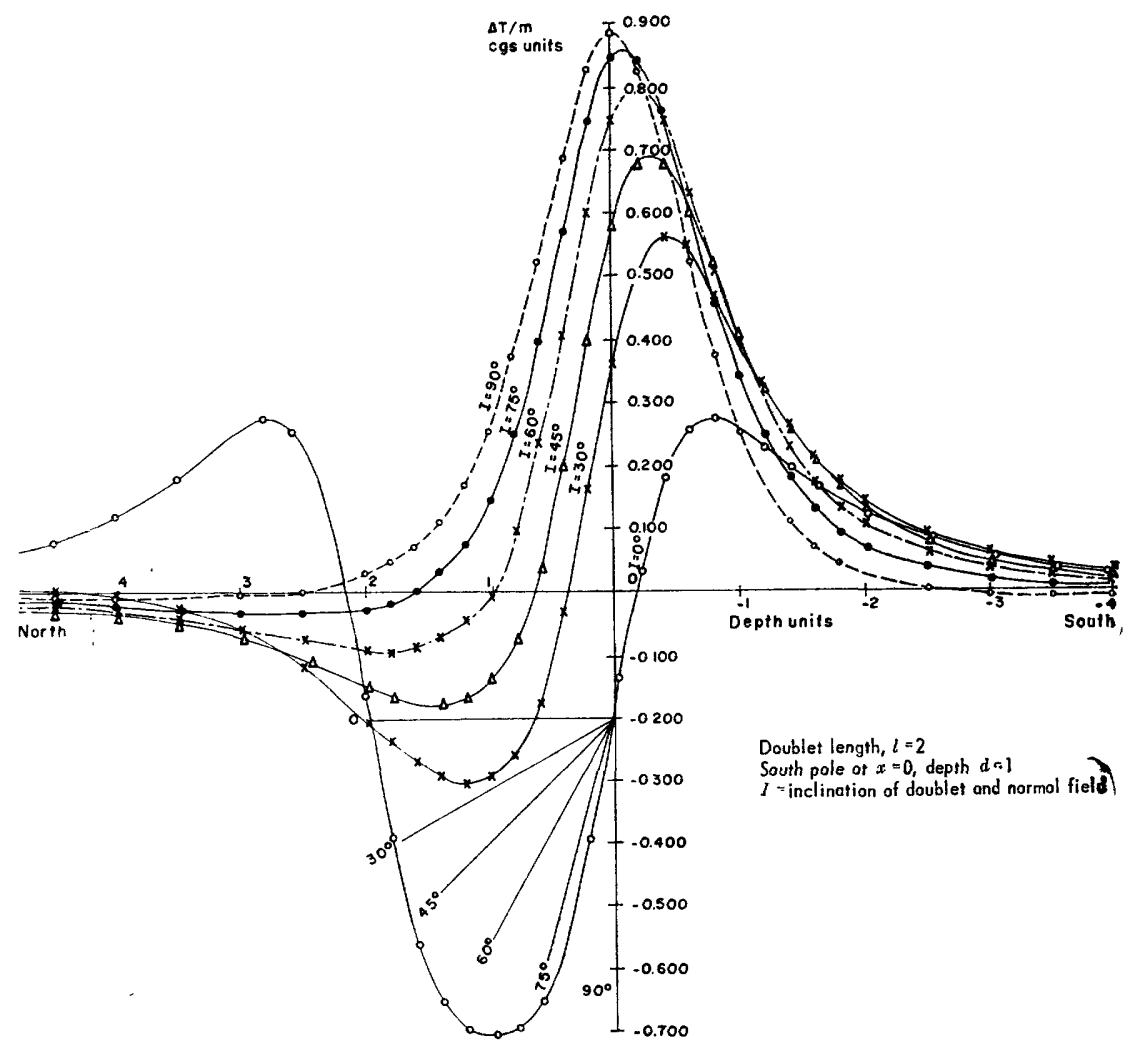

Figure 33. -Total-intensity anomalies of magnetic doublet of length, $l=2$ depth units.

The incremental changes in $\beta_{1}$ are too small to permit us adequately to distinguish among the different terms $l / d$, but those of $\beta_{2}$ are satisfactory for this purpose. If the choice were $\beta=\left(x_{\min }-x_{\max }\right) /$ $\left(x_{\max }-x_{0.8}\right)$, the increments in $\beta$ would be larger, but this gain would be offset by uncertainties in the location of the minimum. Similar studies were made of families of theoretical $\Delta T(x)$ profiles for all the remaining inclinations. Abscissas yielding satisfactory values of $\beta$ and $\delta$ are given in table 2 , together with magnitudes of maximum and minimum values of $\Delta T(x)$ and their respective coordinates. 


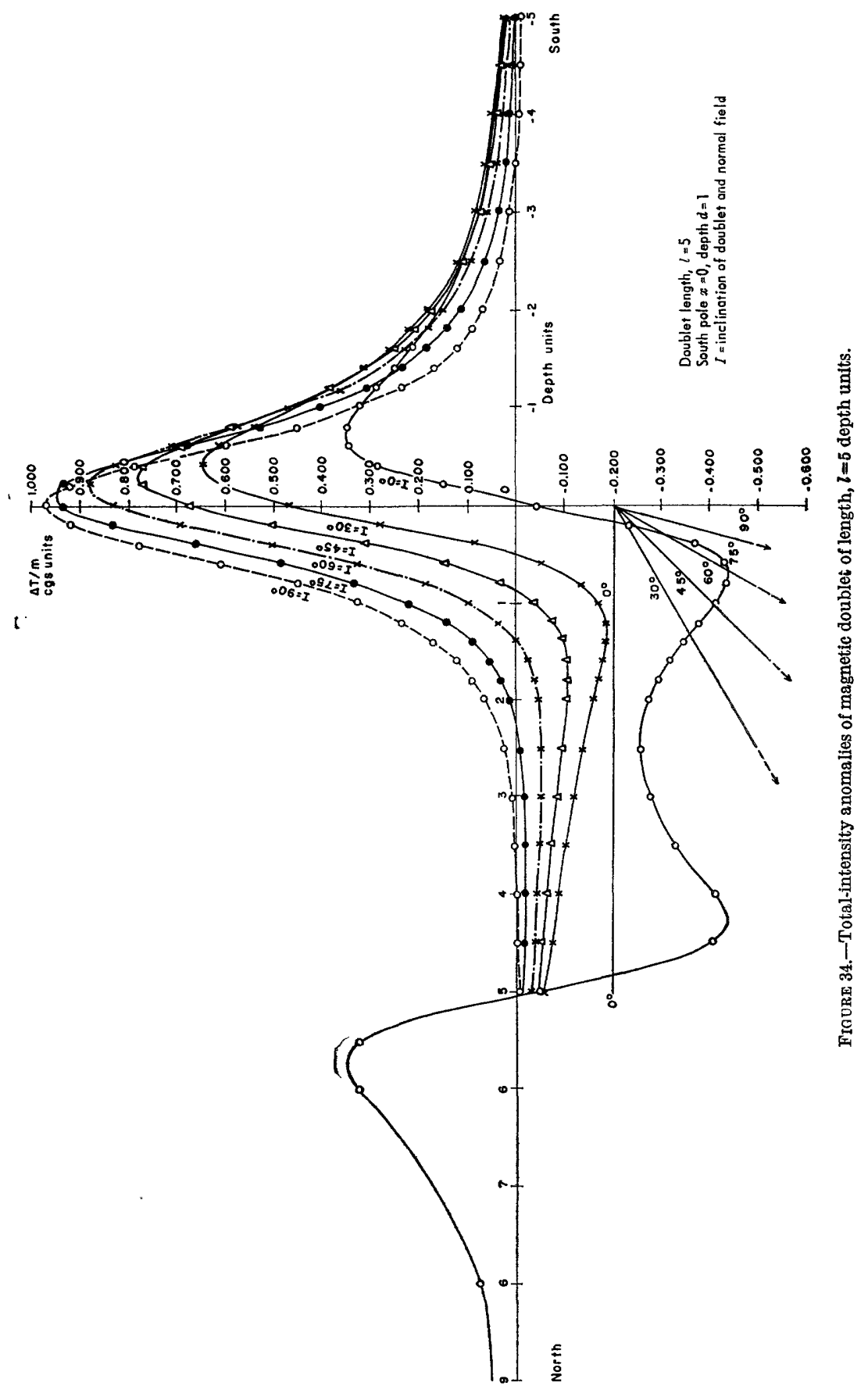




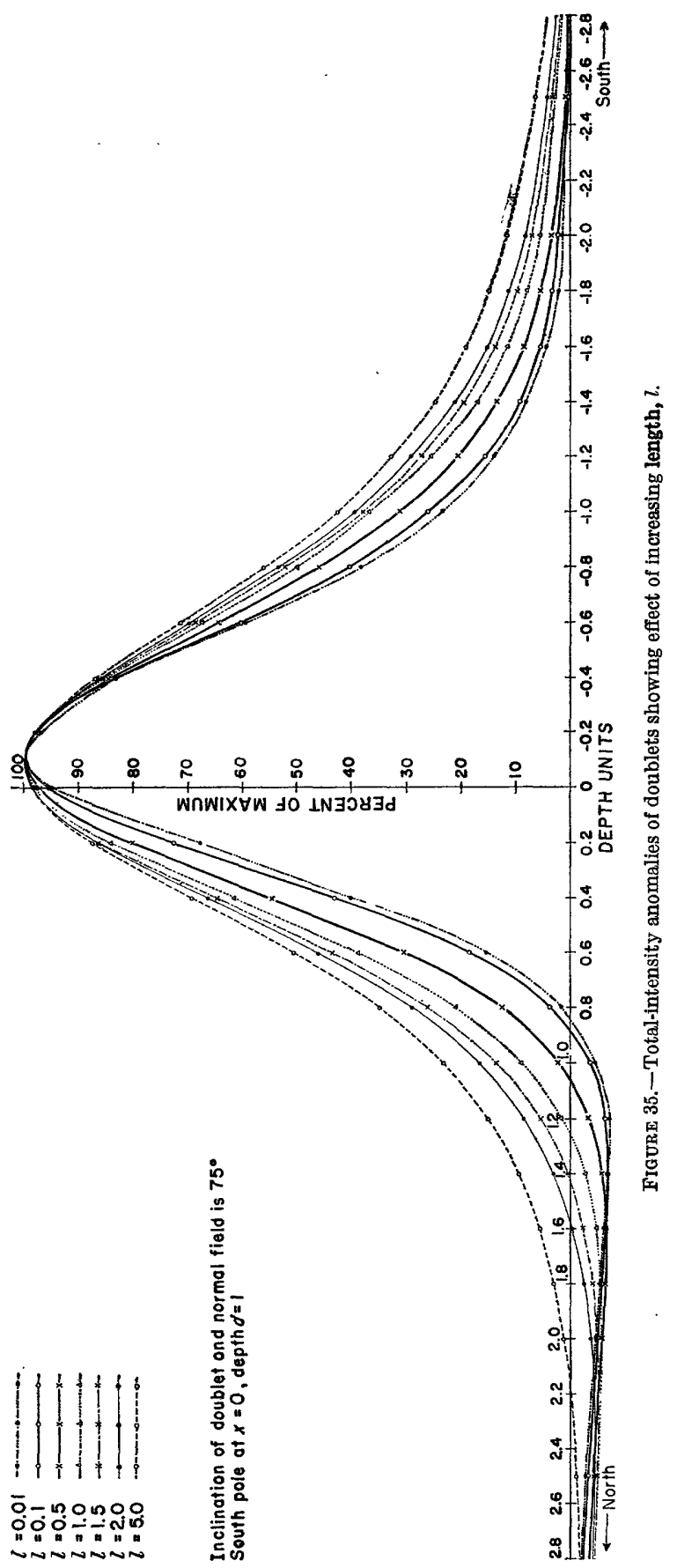


TaBle 2.-Parameters of magnetic doublets for inclinations, $I$, and length-to-depth ratios, $l / d$

The positions $x_{0.1}, x_{0.2}, x_{0.3} \ldots$ indicate, respectively, abscissas of 10 percent, 20 percent, 30 percent . . of the maximum value, $\Delta T_{\mathrm{max}}$, of a given profile. Prime marks refer to more northerly abscissas. Upper pole is at $x=0, d=1$. Pole strength, $m=1$ ]

\begin{tabular}{|c|c|c|c|c|c|c|}
\hline$u d$ & $\Delta T_{\max }$ & $\Delta T_{\min }$ & $x_{\max }$ & $x_{\min }$ & $\boldsymbol{\beta}$ & $\delta$ \\
\hline \multicolumn{7}{|c|}{ Inclination $0^{\circ}$} \\
\hline \multicolumn{7}{|c|}{$\left[\beta=\left(x_{\min }-x_{\max }\right) /\left(x_{\min }-x_{0.8}\right) . \quad \delta=x_{0.8}^{\prime}-x_{0.8}\right]$} \\
\hline 0.01 & 0.002 & -0.010 & -1.20 & 0.01 & 3. 16 & 0. 78 \\
\hline .10 & .020 & -.098 & -1.20 & .05 & 3. 20 & .78 \\
\hline .50 & .098 & -.452 & -1.00 & .25 & 2. 91 & .83 \\
\hline 1. 00 & .180 & -.706 & -.90 & .50 & 2. 80 & 1. 02 \\
\hline 1. 50 & .235 & -.766 & -.80 & .75 & 2. 46 & 1. 28 \\
\hline 2. 00 & .274 & -.707 & -.80 & 1. 00 & 2. 14 & 1. 67 \\
\hline
\end{tabular}

Inclination $30^{\circ}$

$\left[\beta=\left(x_{\min }-x_{\max }\right) /\left(x_{\max }-x_{0.5}\right) . \quad \delta=x_{0.1}^{\prime}-x_{0.1}\right]$

\begin{tabular}{r|r|r|r|r|r|r}
\hline 0.01 & 0.008 & -0.008 & -0.60 & 0.35 & 1.27 & 2.67 \\
.10 & .076 & -.070 & -.58 & .43 & 1.31 & 2.77 \\
.50 & .290 & -.252 & -.53 & .60 & 1.40 & 2.95 \\
1.00 & .440 & -.347 & -.46 & .82 & 1.45 & 3.16 \\
1.50 & .516 & -.332 & -.43 & 1.02 & 1.61 & 3.39 \\
2.00 & .564 & -.306 & -.40 & 1.15 & 1.67 & 3.45 \\
5.00 & .649 & -.185 & -.35 & 1.32 & 1.72 & 3.90 \\
\hline
\end{tabular}

Inclination $45^{\circ}$

$\left[\beta=\left(x_{\min }-x_{\max }\right) /\left(x_{\max }-x_{0.8}\right) . \quad \delta=x_{0.2}^{\prime}-x_{0.2}\right]$

\begin{tabular}{r|r|r|r|r|r|r}
\hline 0.01 & 0.013 & -0.005 & -0.40 & 0.58 & 1.60 & 1.71 \\
.10 & .111 & -.046 & -.35 & .65 & 1.69 & 1.84 \\
.50 & .392 & -.154 & -.35 & .85 & 2.00 & 1.94 \\
1.00 & .440 & -.192 & -.35 & 1.10 & 2.38 & 2.16 \\
1.50 & .638 & -.192 & -.35 & 1.30 & 2.66 & 2.30 \\
2.00 & .690 & -.178 & -.35 & 1.50 & 2.94 & 2.40 \\
5.00 & .780 & -.104 & -.35 & 1.80 & 3.77 & 2.66 \\
\hline
\end{tabular}


TABLE 2.-Parameters of magnetic doublets for inclinations, $I$, and length-to-depth ratios, $l / d$-Continued

\begin{tabular}{|c|c|c|c|c|c|c|}
\hline$l / d$ & $\Delta T_{\max }$ & $\Delta T_{\min }$ & $x_{\mathrm{max}}$ & $x_{\min }$ & $\beta$ & $\delta$ \\
\hline \multicolumn{7}{|c|}{ Inclination $60^{\circ}$} \\
\hline \multicolumn{7}{|c|}{$\left[\beta=\left(x_{0.1}-x_{\max }\right) /\left(x_{\max }-x_{0.8}\right)\right.}$. \\
\hline 0.01 & 0.017 & -0.003 & -0.24 & 0.85 & 1.65 & 1.05 \\
\hline 0.10 & .142 & -.026 & -.26 & 1.00 & 2. 12 & 1. 06 \\
\hline 0.50 & .480 & -.081 & -.22 & 1. 20 & 2. 14 & 1. 19 \\
\hline 1. 00 & .662 & -.098 & -.20 & 1. 40 & 2. 32 & 1. 29 \\
\hline 1. 50 & .750 & -.096 & -.19 & 1. 68 & 2. 42 & 1. 36 \\
\hline 2. 00 & .801 & -.089 & -.19 & 1. 80 & 2. 58 & 1. 40 \\
\hline 5. 00 & .882 & -.050 & -.18 & 2. 50 & 2. 79 & 1. 48 \\
\hline
\end{tabular}

Inclination $\mathbf{7 5}^{\circ}$

$\left[\beta=\left(x_{0.1}^{\prime}-x_{\max }\right) /\left(x_{\max }-x_{0.8}\right) . \quad \delta=x_{0.5}^{\prime}-x_{0.5}\right]$

\begin{tabular}{r|r|r|r|r|r|r}
\hline 0.01 & 0.018 & -0.001 & -0.12 & 1.20 & 2.52 & 1.01 \\
.10 & .163 & -.011 & -.13 & 1.40 & 2.68 & 1.05 \\
.50 & .540 & -.033 & -.11 & 1.60 & 2.79 & 1.19 \\
1.00 & .730 & -.040 & -.10 & 2.00 & 3.00 & 1.30 \\
1.50 & .817 & -.038 & -.10 & 2.30 & 3.19 & 1.37 \\
2.00 & .865 & -.043 & -.09 & 2.50 & 3.21 & 1.41 \\
5.00 & .950 & -.021 & -.09 & 3.50 & 3.59 & 1.50 \\
\hline
\end{tabular}

Inclination $90^{\circ}$

$\left[\beta=x_{0.05}^{\prime}-x_{0.5} . \quad \delta=x_{0.5}\right]$

\begin{tabular}{|c|c|c|c|c|c|c|}
\hline 0. 01 & 0.020 & 0.000 & 0 & 1. 90 & 2. 22 & 0. 51 \\
\hline .10 & .174 & -.003 & 0 & 2. 00 & 2.25 & .52 \\
\hline .50 & .556 & -.019 & 0 & 2. 50 & 2. 25 & .60 \\
\hline 1. 00 & .750 & -.011 & 0 & 3. 00 & 2. 38 & . \\
\hline 1. 50 & .840 & -.011 & 0 & 3.50 & 2. 46 & .68 \\
\hline 2. 00 & .889 & -.010 & 0 & 3.50 & 2. 57 & .70 \\
\hline 5. 00 & .938 & -.005 & 0 & 5. 70 & 2. 91 & .75 \\
\hline
\end{tabular}




\section{ANALYSIS OF ANOMAIIES}

To determine the magnetic-doublet equivalent of a suitable observed anomaly, a north-south profile is drawn through the maximum at any convenient scale. The zero datum line is drawn by inspection and is based on the mean undisturbed magnetic level. The magnetic inclination for the area is determined from isoclinal charts published by the U. S. Coast and Geodetic Survey (Deel and Howe, 1948) or from tables by Vestine and others (1947). The abscissas to be used in computing $\beta$ are taken from table 2 , for the inclination nearest to that observed. If the computed value of $\beta$ falls within the range of those listed in the table, there is reason to believe that a doublet representation by the method described here is possible. Table 2 is entered for this value of $\beta$ and a quantity $l / d$ and a depth factor $\delta$ are determined by interpolation. The depth, $d$, to the near pole is calculated by dividing the corresponding horizontal distance on the observed profile by $\delta$. The doublet length is then obtained from the product of $d$ and $l / d$.

The calculation is best explained by an example. Consider the total-intensity profile over the inclined cylinder shown in figure 36, which was obtained from experiments on models. As the inclination

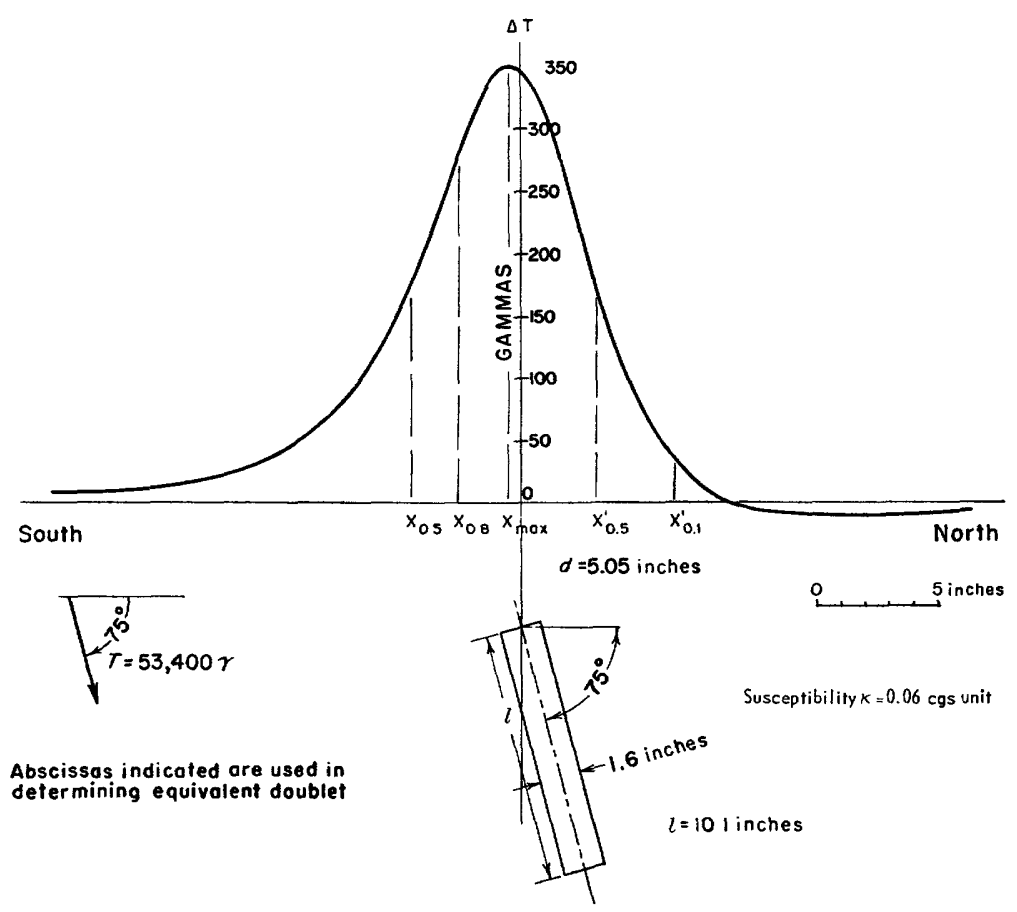

FIGURE 36.-Total-intensity anomaly of inclined cylinder; obtained from model experiment. 
is $75^{\circ}$, the abscissas to be used in computing $\beta$ and $\delta$ are $x_{\max }, x^{\prime}{ }_{0.1}$, $x_{0.5}, x^{\prime}{ }_{0.5}$ and $x_{0.8}$, as indicated by table 2 . The maximum value of $\Delta T$ is $350 \gamma$; therefore the $x$ coordinates for $35 \gamma, 175 \gamma, 280 \gamma$, and $350 \gamma$ are plotted as shown. Then $\beta=\left(x_{0.1}^{\prime}-x_{\max }\right) /\left(x_{\max }-x_{0.8}\right)=3.24$. Entering table 2 for $\beta=3.24$ we obtain by interpolation an $l / d$ of 2.2 and a $\delta$ of 1.42 inches. As $x^{\prime}{ }_{0.5}-x_{0.5}=7.30$ inches on the profile, the depth is $d_{c}=\left(x_{0.5}^{\prime}-x_{0.5}\right) / \delta=(7.30) /(1.42)=5.1$ inches. The length is $l_{s}=$ $(l / d) d_{c}=(2.2)(5.1)=11.2$ inches. The depth and length are known to be $d_{o}=5.05$ inches and $l_{o}=10.1$ inches from model experiments. The results are unusually good even for a carefully controlled laboratory experiment.

\section{OTHER USES OF COMPUTED ANOMAIIES}

Although figures 28 to 34 were computed primarily for determining the $\beta$ and $\delta$ factors, they can be used for qualitative interpretations. For example, they provide information on the general shape of totalintensity anomalies to be expected from different rock masses magnetized by induction. When the horizontal dimensions of the mass are less than the depth to its top, a single doublet can be used to represent it. When the mass has a width less than the depth, but is extensive in the plane of the magnetic meridian, the anomalies of several doublets alined in parallel in the meridian can be combined to give an equivalent anomaly. This simple addition of two or more anomalies is permissible by the superposition law of potential theory.

The following generalizations based on figures 28 to 35 are helpful in interpretations:

1. The anomaly of the vertical doublet is symmetric with respect to the axis.

2. For inclined doublets, the maximum of an anomaly is always south of the upper pole, and the amount of the south shift increases with decrease in the inclination.

3. For a given depth and doublet length, a decrease in the inclination diminishes the amplitude of the maximum and increases that of the minimum. The effect on the steepest gradients is practically negligible, and the north slopes of the profile remain parallel for all inclinations. The latter fact suggests that fitting a slope is meaningless, because the diagnostic characteris tics of the anomaly are involved in the south slope and minimum as well.

4. If other parameters are equal, an increase in doublet length decreases the steepest gradients of the anomaly, as can be seen explicitly in figure 25.

5. For an inclination $I=0$, a double minimum develops when $l$ is about three times the depth, which indicates resolution of the effects of the two poles. 
6. For $l$ very large, the theory reduces to that of a point pole, which we have already treated (Henderson and Zietz, 1948).

\section{MAGNETIC MODEL EXPERIMENTS}

To investigate the method of study when applied to fields produced by physically realizable bodies, a series of experiments on magnetic models was carried out. Facilities of the Naval Ordnance Laboratory at White Oak, Md., were made available for these and other tests. A detailed account of the experiments is contained in a preliminary report by Zietz and Henderson (1956).

The experimental set up is an elaborate modification of that used by Alldredge and Dichtel (1949) in their interpretation of the Bikini magnetic data. Three large mutually perpendicular Helmholtz-type coils on 30-foot frames are individually energized by an adjustable d-c voltage supply. In this way, the magnitude and direction of the uniform field of the earth can be simulated over a relatively large volume about the center of the system. A model is placed at the center and the anomaly field produced by the induced magnetism of the model is measured by means of a flux-gate magnetic detector of fixed orientation on a tower having powered vertical positioning. The detector tower is mounted on a carriage which moves in an eastwest or a north-south direction. Continuous registration of data is accomplished with a null-type recorder. Once the model has been set up and the detector oriented in the direction of the simulated field, all operations are conveniently effected from control panels mounted in a console. The accuracy of the magnetometer system is $\pm 3 \gamma$.

The models were prepared from a mixture of gypsum plaster and powdered magnetite in the ratio of $2: 1$ by volume. For this study, the models were primarily cylinders; however, a few double-layer models 0.5 inch thick were also used. All remanent magnetism in the models was carefully removed by electrical "shaking" in a zero ambient field. The cylinders and the detector were alined codirectionally with the field at the center of the Helmholtz system. The applied total field was invariably $53,400 \gamma$.

\section{TESTS ON CYIINDRICAI MODEIS}

A profile of a typical $\Delta T$ anomaly over a cylinder is shown in figure 36 together with data for computation. Similar profiles for 5 cylinders in fields of inclinations $I=0^{\circ}, 75^{\circ}$, and $90^{\circ}$ were also analyzed and the results are given in table 3 . The measured length of the cylinder and depth to the center of the base nearer the origin are in columns headed " $l_{o}$ " and " $d_{o}$ " and the corresponding computed lengths and 
depths are in columns " $l_{c}$ " and " $d_{c} . "$ In general the calculated depths are in better agreement with those measured than are the calculated lengths.

TABLE 3.-Comparison of calculated doublet lengths and depths with those used in model experiments

[Dip of cylinders equal to inclination of impressed field. Linear dimensions in inches]

\begin{tabular}{|c|c|c|c|c|c|c|c|c|}
\hline \multirow{2}{*}{$\begin{array}{c}\text { Inclina- } \\
\text { tlon }\end{array}$} & \multirow{2}{*}{$\begin{array}{l}\text { Oylinder } \\
\text { No. }\end{array}$} & \multirow{2}{*}{ Diameter } & \multicolumn{3}{|c|}{ Observed values } & \multicolumn{3}{|c|}{ Computed values } \\
\hline & & & t. & do & $(a / d)$. & $(l / d)$. & $\boldsymbol{l}_{\boldsymbol{\sigma}}$ & $\boldsymbol{d}_{\boldsymbol{\theta}}$ \\
\hline \multirow[t]{11}{*}{$0^{\circ}$} & \multirow[t]{3}{*}{ I } & 2. 15 & 5. 00 & 4. 90 & 1.02 & 1. 3 & 5. 5 & 4. 2 \\
\hline & & 2. 15 & 5. 00 & 6. 80 & .74 & 1. 0 & 5. 8 & 5. 8 \\
\hline & & 2. 15 & 5. 00 & 8. 50 & .59 & 1. 1 & 7. 7 & 7. 0 \\
\hline & \multirow[t]{2}{*}{ II } & 1. 00 & 5. 10 & 3. 70 & 1. 38 & 1.8 & 5.4 & 3. 0 \\
\hline & & 1.00 & 5. 10 & 5. 75 & .89 & 1.8 & 7. 7 & 4. 4 \\
\hline & \multirow[t]{2}{*}{ III } & 4. 05 & 10.00 & 9.00 & 1. 11 & 1. 5 & 11. 2 & 7. 5 \\
\hline & & 4. 05 & 10. 00 & 14.20 & .70 & 1. 2 & 14.8 & 12. 3 \\
\hline & \multirow[t]{2}{*}{ IV } & 1. 60 & 10. 10 & 6. 45 & 1. 57 & 1.8 & 10. 8 & 6. 2 \\
\hline & & 1.60 & 10. 10 & 11.50 & .88 & 1.8 & 15. 1 & 8. 4 \\
\hline & \multirow[t]{2}{*}{$\mathbf{V}$} & 1. 50 & 18. 00 & 5. 85 & 3. 08 & 3. 8 & 17. 1 & 4. 5 \\
\hline & & 1. 50 & 18. 00 & 7. 35 & 2. 45 & 2. 9 & 21.5 & 7. 4 \\
\hline \multirow[t]{6}{*}{$30^{\circ}$} & \multirow[t]{2}{*}{ I } & 2. 15 & 5. 00 & 3. 75 & 1. 33 & 1. 2 & 5. 2 & 4. 3 \\
\hline & & 2. 15 & 5. 00 & 5. 65 & .88 & 1. 1 & 7. 4 & 7. 0 \\
\hline & II & 1. 00 & 5. 10 & 3. 15 & 1. 62 & 1.2 & 4. 2 & 3. 5 \\
\hline & III & 4. 05 & 10.00 & 5. 00 & 2. 00 & 1.2 & 9.5 & 7. 9 \\
\hline & IV & 1. 60 & 10. 10 & 5. 70 & 1. 77 & .8 & 6. 4 & 7. 7 \\
\hline & V & 1. 50 & 18. 00 & 4. 92 & 3. 66 & 3. 5 & 20.7 & 5. 9 \\
\hline \multirow[t]{6}{*}{$75^{\circ}$} & \multirow[t]{2}{*}{ I } & 2. 15 & 5. 00 & 5.00 & 1.00 & .9 & 4. 9 & 5. 3 \\
\hline & & 2. 15 & 5. 00 & 6.65 & .75 & 1. 4 & 9. 1 & 6. 4 \\
\hline & III & 4. 05 & 10.00 & 5. 00 & 2. 00 & 2. 6 & 14.6 & 5. 6 \\
\hline & \multirow[t]{2}{*}{ IV } & 1. 60 & 10. 10 & 5. 05 & 2. 00 & 2. 2 & 11. 1 & 5. 1 \\
\hline & & 1. 60 & 10. 10 & 10.10 & 1. 00 & 1,1 & 11. 1 & 10.0 \\
\hline & V & 1. 50 & 18.00 & 4. 50 & 4.00 & 5. 7 & 25. 6 & 4. 5 \\
\hline \multirow[t]{6}{*}{$90^{\circ}$} & I & 2. 15 & 5. 00 & 4. 50 & 1. 11 & 1. 8 & 7. 9 & 4. 5 \\
\hline & II & 1. 00 & 5. 10 & 4. 60 & 1. 11 & 1. 5 & 6. 6 & 4. 4 \\
\hline & \multirow{2}{*}{ III } & 4. 05 & 10. 10 & 5. 00 & 2. 02 & 2. 6 & 14.6 & 5. 6 \\
\hline & & 4. 05 & 10. 10 & 10.00 & 1. 01 & 1. 5 & 15. 0 & 10.0 \\
\hline & V & 1. 50 & 18. 00 & 4. 00 & 4. 50 & 5. 0 & 21.5 & 4. 3 \\
\hline & VI & 5. 85 & 9. 90 & 5. 05 & 1. 96 & 1. 2 & 7.8 & 6. 5 \\
\hline
\end{tabular}

Comparisons of columns $(l / d)_{\circ}$ and $(l / d)_{c}$ also afford some idea of the accuracy involved. Calculations of doublet length are more reliable for low magnetic inclinations than for high inclinations. In low inclinations the more remote source is nearer the surface and can therefore have a greater expression in the data. 
Uncertainties in the location of apparent poles of a cylindrical body impose limitations on the extent to which comparisons of observed and computed values of $l$ and $d$ can be made. Theoretically, at least, it is expected that $d_{c}$ will be greater than $d_{o}$ and $l_{c}$ will be less than $l_{o}$, because the apparent poles must lie within the body. In this particular investigation, the errors developed in the process rendered indiscernible any such systematic trends.

For a given cylinder the errors in computed lengths and depths increase as $l / d$ decreases, which is to be expected. The depth $d_{c}$ in table 3 was computed with a mean error of 14 percent; the $l_{c}$ was computed with a mean error of 29 percent.

\section{MAGNETIC DOUBLE-LAYER MODELS}

The method was applied to anomaly fields measured over models consisting of plaster-magnetite horizontal slabs 0.5 inch thick and of different rectangular dimensions. The 5 inches $\times 5$ inches model at a depth of 5 inches gave fair results, as shown in table 4 . Here, the doublet length, $l$, is logically the slant distance in inches (see inset, fig. 37) measured along the direction of the field between the upper and lower faces, and is given by $l_{o}=5 / \cos I$ for $0 \bar{\Sigma} I \overline{2} 0.032 \pi$ and

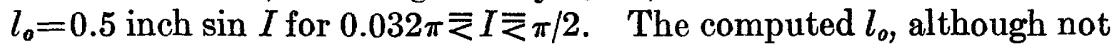
entirely satisfactory for determining the thickness, does in a general way decrease with increasing $I$ and gives the order of magnitude. The results suggest that the calculation of depth to the top surface is more

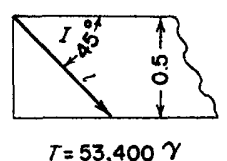

Iinch Depth scale

All linear dimensions in inches

Susceptibility $k=0.06$ cgs unit

$T=53,400 \gamma$

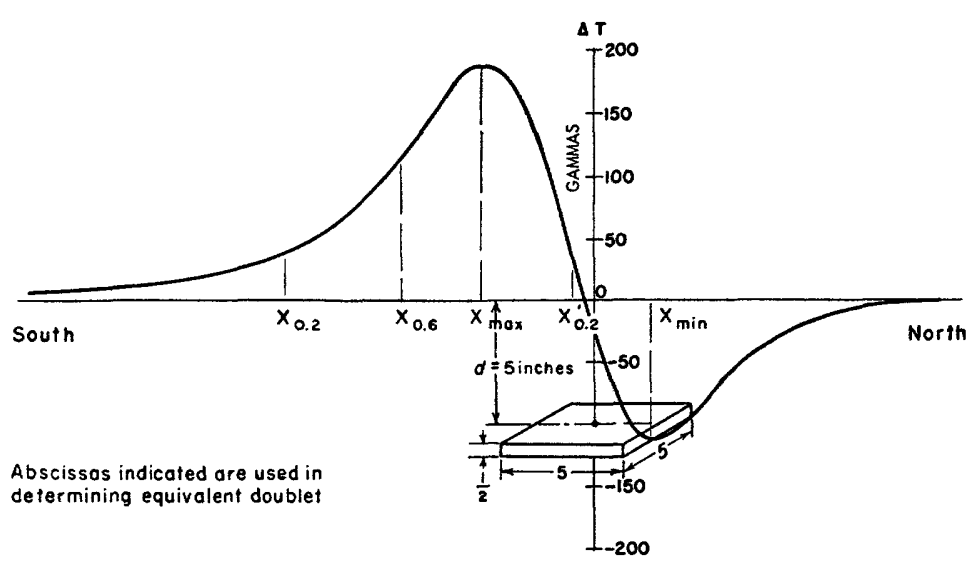

FIGURE 37.-Total-intensity anomaly of magnetized plate; obtained from model experiment. 
accurate at low magnetic inclinations. When applied to doublelayer models of larger horizontal dimensions, for example, 0.5 inch $\times 10$ inches $\times 10$ inches, the method failed, because the $\beta$ values fell outside the range of table 2 . For models 0.5 inch thick but of plan less than 5 inches $\times 5$ inches, the method would very likely be successful.

TABLE 4.-Application of magnetic-doublet theory to field of horizontal slab

[Fields obtained from laboratory measurements on body of dimensions 0.5 in. $\times 5$ in. $\times 5$ in. at a depth of 5 in. Linear dimensions in inches]

\begin{tabular}{|c|c|c|c|c|c|}
\hline Inclination $\mathbf{t}$ & Model & $(l / d)$ 。 & $(l / d)$ 。 & $l_{0}$ & $d_{0}$ \\
\hline $0^{\circ}$ & 5. 00 & 1.00 & 1. 12 & 5. 5 & 4. 9 \\
\hline $30^{\circ}$ & 1. 00 & .20 & .60 & 3. 3 & 5. 0 \\
\hline $45^{\circ}$ & .85 & .17 & .56 & 3. 2 & 5. 8 \\
\hline $60^{\circ}$ & .58 & .11 & .10 & .6 & 6. 3 \\
\hline $75^{\circ}$ & .52 & .10 & .20 & 1. 2 & 6. 2 \\
\hline
\end{tabular}

1 Observations over the center line at $I=90^{\circ}$ were not made.

Some idea of the limits of the size of bodies that can be analyzed in this manner can be gained from the following expression for the $\Delta Z$ anomaly on the axis of a vertical cylinder in a vertical field:

$$
\Delta Z(0)=2 \pi \kappa Z_{o}\left\{(d+l) /\left[(d+l)^{2}+\rho^{2}\right] \frac{1}{2}-d /\left(d^{2}+\rho^{2}\right) \frac{1}{2}\right\}
$$

where $Z_{\mathrm{o}}$ is the impressed vertical intensity field, $\rho$ the radius, $d$ the depth to the upper base, and $\kappa$ the susceptibility. If the expression (2) is expanded in a binomial series the result is

$$
\Delta Z(O)=2 \pi k Z_{o}\left\{\left(\frac{1}{2}\right)\left[\rho^{2} / d^{2}-\rho^{2} /(d+l)^{2}\right]-\frac{3}{8}\left[\rho^{4} / d^{4}-\rho^{4} /(d+l)^{4}\right]+\ldots\right\}
$$

which is valid for $\rho<d$. For $\rho \ll d$ only the first term is significant and (3) may be written

$$
\text { (cylinder) } \quad \Delta Z(0) \approx \pi_{\kappa} Z_{\odot} \rho^{2}\left[1 / d^{2}-1 /(d+l)^{2}\right] .
$$

The expression (4) has the same geometrical form as the formula for a vertical doublet in a vertical field:

$$
\Delta Z(0)=m\left[1 / d^{2}-1 /(d+l)^{2}\right] .
$$

Although (4) and (5) are meaningful only at the origin, and although $l$ for the cylinder is not identical with $l$ for the doublet, the comparison nevertheless suggests that the mean radius of a body must be less than its depth of burial if it is to be successfully represented as a magnetic doublet. The experiment above on the 5 inches $\times 5$ inches body at a depth of 5 inches, with an effective radius $\rho=5 / \sqrt{\pi}$ confirms 


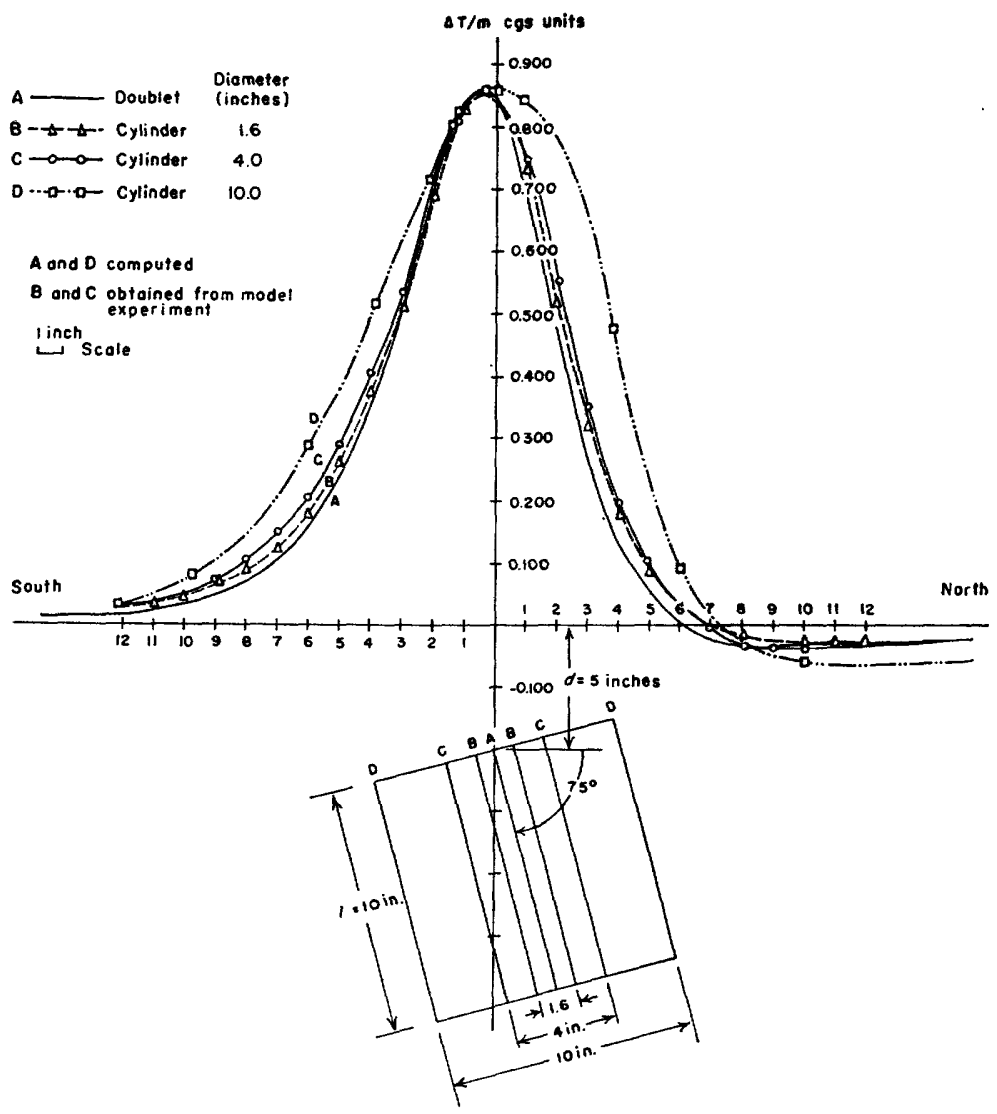

MAXIMUNS HAVE BEEN AD JUSTED TO DOUBLET WITH ' $T$ a -0.865 egs unt

Findre 38.-Anomalies of inclined cylinders showing effect of increasing diameter.

this result. In the 10 inches $\times 10$ inches body at the same depth, the effective radius is $\rho=10 / \sqrt{\pi}$ and failure is to be expected.

To investigate further the effect of the radius on doublet representation, the anomalies of 3 coaxial cylinders 10 inches long in a field of inclination $75^{\circ}$ were adjusted so that the $\Delta T_{\max }$ of each was equal to that of a doublet of the same length, as shown in figure 38. For all, the depth to the center of the top is $d$ and the length $2 d$. The radii of cylinders $B, C$, and $D$ are $\rho=0.16 d, 0.4 d$, and $d$. The anomalies of $B$ and $C$ were obtained from model experiments. The doublet anomaly was computed from formula (1). The anomaly for cylinder $D$ was computed numerically by means of a modification 
(Henderson, R. G., and Zietz, Isidore, 1958) of Gassman's threedimensional integration process (Gassman 1951). The latter was checked by application to cylinder $C$ whose anomaly it reproduced faithfully. In figure 38 , it is quite clear that the shape of the anomaly does not alter radically from that of a doublet as the radius increases to 0.4 depth. When the radius equals the depth, the shape of the anomaly bears little resemblance to that of a doublet; therefore the doublet-analysis method cannot be used. It also appears from figure 38 that the possibility of determining the radius of a cylinder from a dipolelike anomaly is very remote. A rigorous investigation of this matter is not possible because of the lack of a closed form for calculating the $\Delta T$ anomaly of a cylinder.

\section{PRACTICAL APPLICATIONS}

Aeromagnetic observations over geologic bodies of known depth, dimensions, and magnetic properties were not available for testing. The method was therefore applied to the surveys in areas for which we have some knowledge, although fragmentary, of the depth to crystalline magnetic rocks. If the rocks are exposed, the problem is simply to determine from magnetic data the altitude of the surveying airplane above the surface. In other areas where the crystalline rocks are buried, the "known" depths can be inferred from drilling data or from geologic information. Although calculations of $l$ were made, the results are not included here because depth-extent data for purposes of comparison were nonexistent.

The anomalies to which we have applied this method are shown in figures 39 to 43 . The line $A-A^{\prime}$ in each figure indicates the profile across the anomaly, and $B-B^{\prime}$ indicates the horizontal distance used with the appropriate $\delta$ in the depth calculation. The values of $\beta$ are not shown for these applications.

\section{SOUTHEAST MISSOURI}

On the U. S. Geological Survey aeromagnetic map of the Coldwater quadrangle, in southeastern Missouri (fig. 39), there are several anomalies over exposed felsite, particularly where the felsite is in contact with granite. Calculations of the depth of the source were made on the closed magnetic high about 1 mile west of Cedar Mountain in the Coldwater quadrangle and a depth of 870 feet was obtained. As the elevation of the airplane above the surface was 800 feet, the calculated value is regarded as satisfactory. 


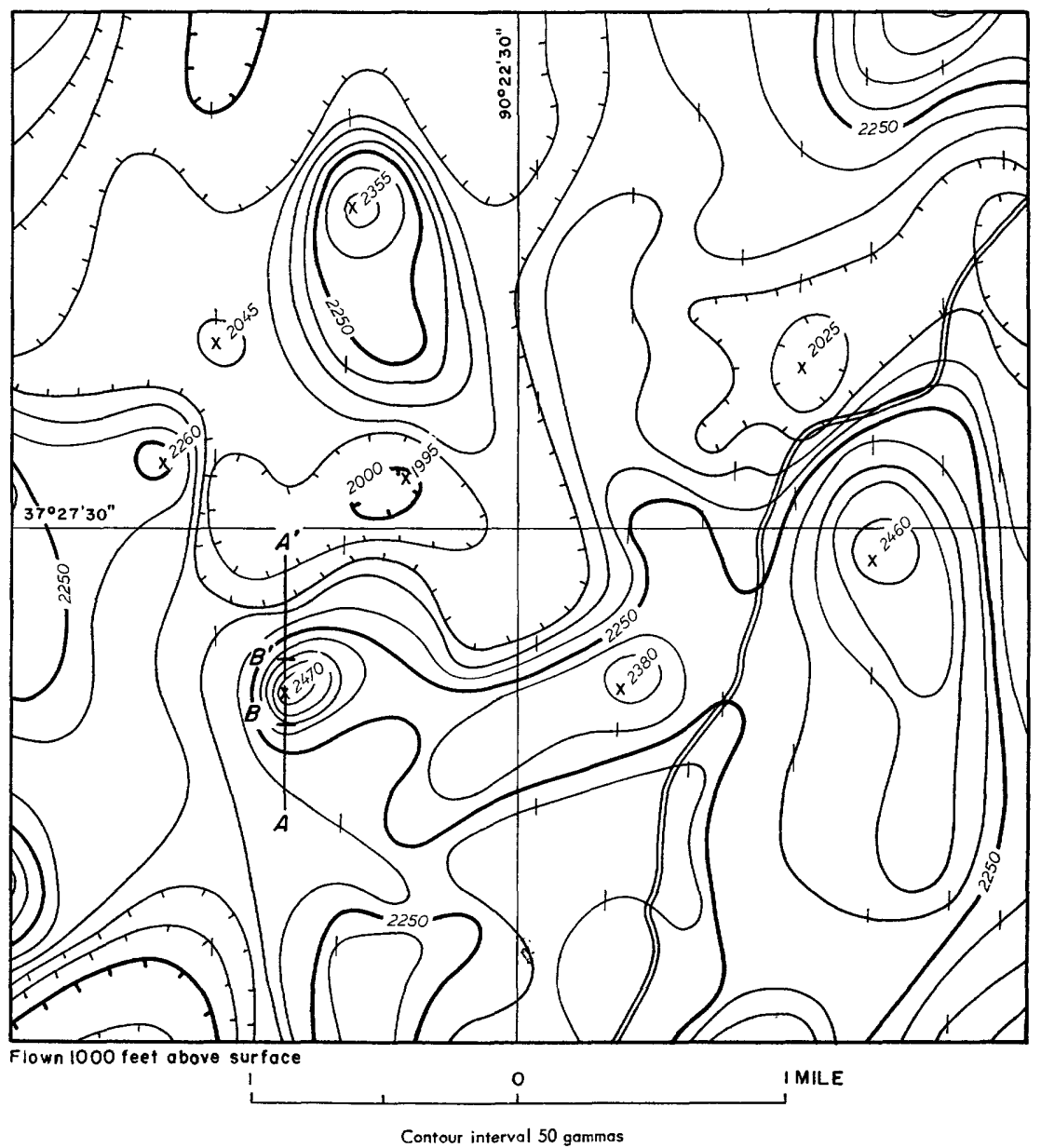

$B-B^{\prime}$ HALF-MAXIMUM DISTANCE ON PROFILE $A-A^{\prime}$

FrGURE 39.-Total-intensity aeromagnetic map of part of Coldwater quadrangle, Missourl. 


\section{INDIANA}

The anomaly near Bryant in T. 24 N., R. 14 E., in Jay County, Ind. (fig. 40), was analyzed by the doublet method and a depth to magnetic rocks of 5,400 feet below the aircraft was found. On the basis of a well in sec. 9, T. 24 N., R. 13 E., Precambrian igneous rocks in the area are estimated to be at a depth of 3,350 feet, or 4,350 feet below the level of observations.

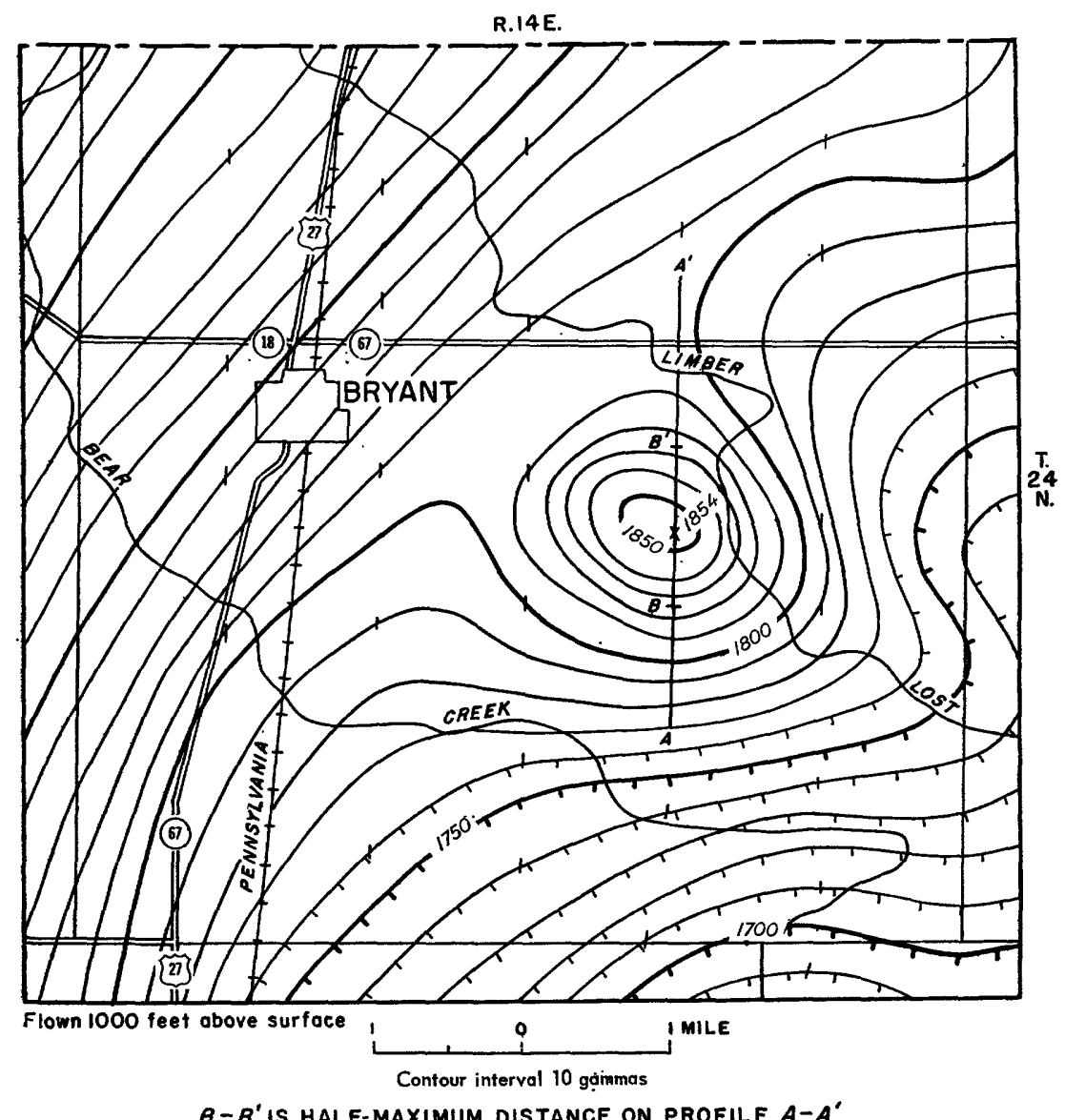

Ficune 40.-Total-intensity aeromagnetic map of area near Bryant, Jay County, Ind. 
In La Porte County, Ind. (fig. 41), information on depth to igneous rocks is scanty, as the nearest wells are about 50 miles away. Geologists estimate the depth to the Precambrian is 6,200 feet at the location of the anomaly 6 miles northeast of La Crosse, in T. 34 N., R. $3 \mathrm{~W}$. The depth calculated by doublet analysis is 6,900 feet below the airplane.

R.3W.

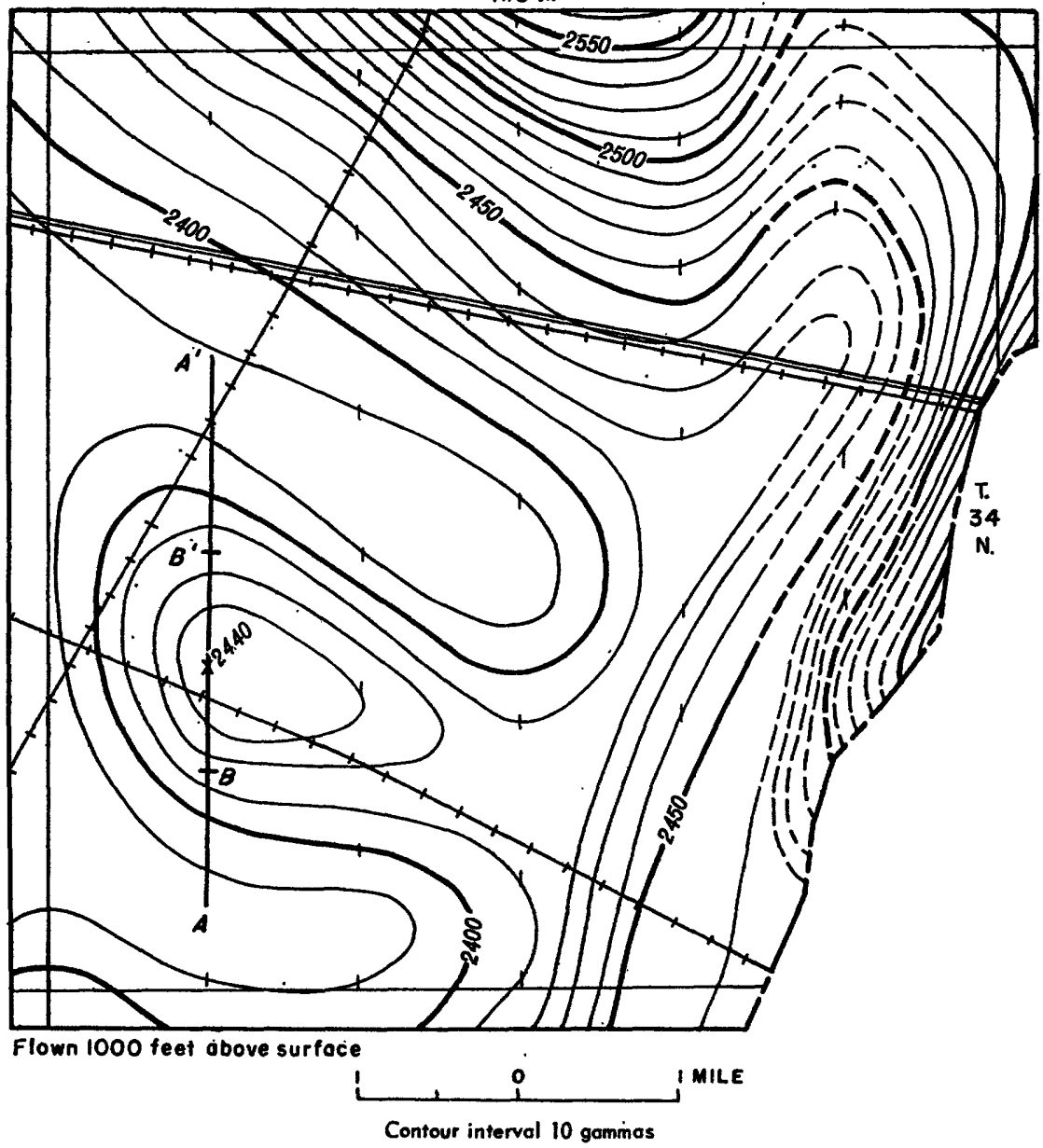

$B-B^{\prime}$ IS HALF-MAXIMUM DISTANCE ON PROFILE $A-A^{\prime}:$

Finure 41.-Total-intensity aeromagnetie map of T. 34 N., R. 3 W., La Porte County, Ind. 


\section{ontario, CANAda}

A prominent magnetic anomaly about 1 mile southeast of Marmora, Ontario, appears on the Campbellsford aeromagnetic map (Canada Geological Survey [1950]). Drilling information indicates there are 90 to 150 feet of limestone of Paleozoic age overlying iron-bearing Precambrian rocks in the area. The disturbing rocks are known to contain magnetite, A calculation on the northeasterly profile $\left(A-A^{\prime}\right.$ in fig. 42) gave a depth of 850 feet below the airplane in comparison with probable depths of 600 to 650 feet.

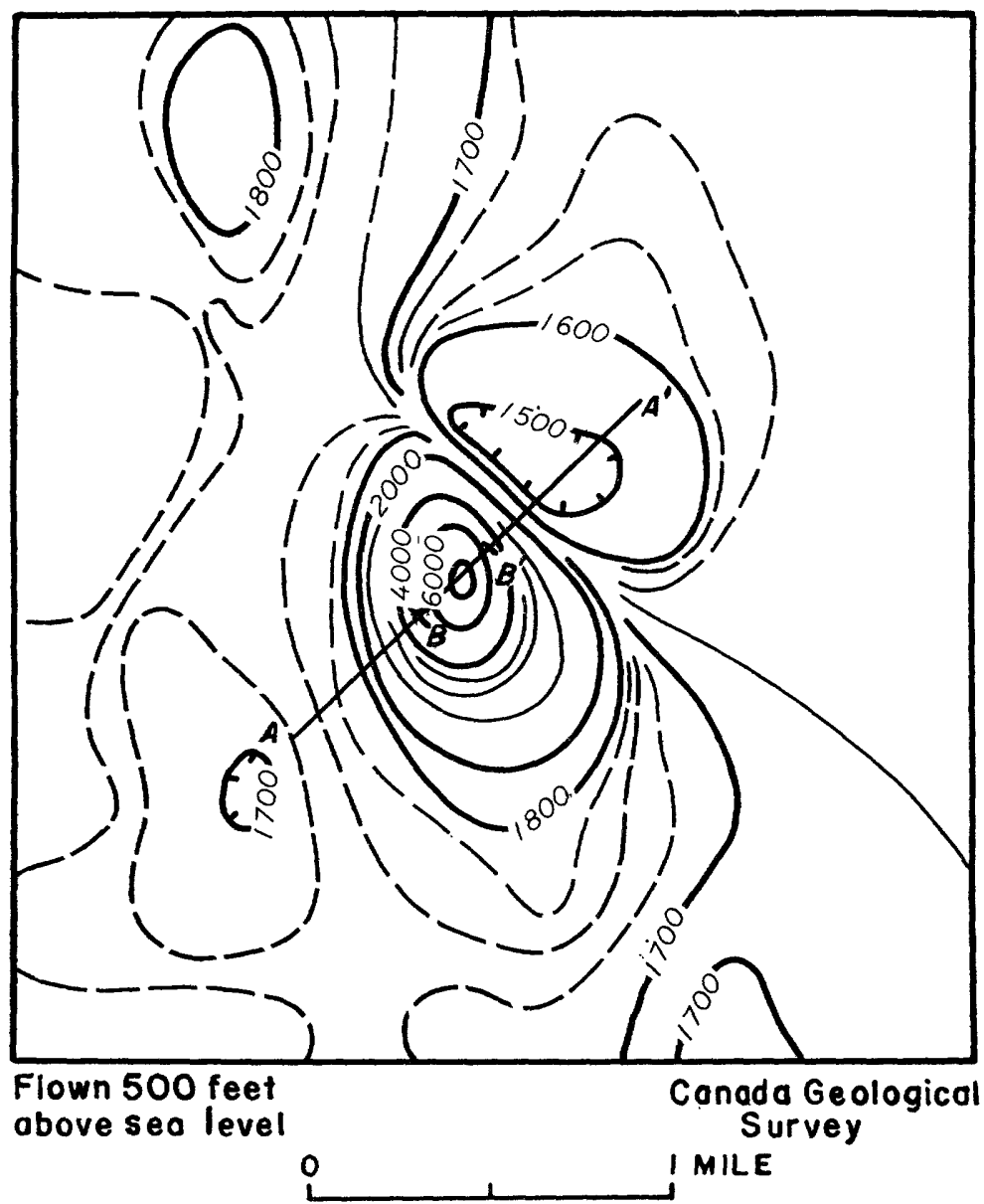

Contour intervals $25,100,200,500$, and 2,000 gammas $B-B^{\prime}$ IS HALF-MAXIMUM DISTANCE ON PROFILE $A-A^{\prime}$

Frcure 42.-Total-intensity aeromagnetic map of area near Marmora, Ontario, Canada. 


\section{ADIRONDACK MOUNTAINS, N. Y.}

Analysis of the isolated magnetic anomaly in the north-central part of the Stark quadrangle in the Adirondack Mountains, (fig. 43) indicated a depth of 1,050 feet for the source. The airplane was 1,000 feet above the ground. The rocks in the area have been mapped as hornblende granite with a few layers of metasediment. It is very likely that the disturbing rocks are near the surface.

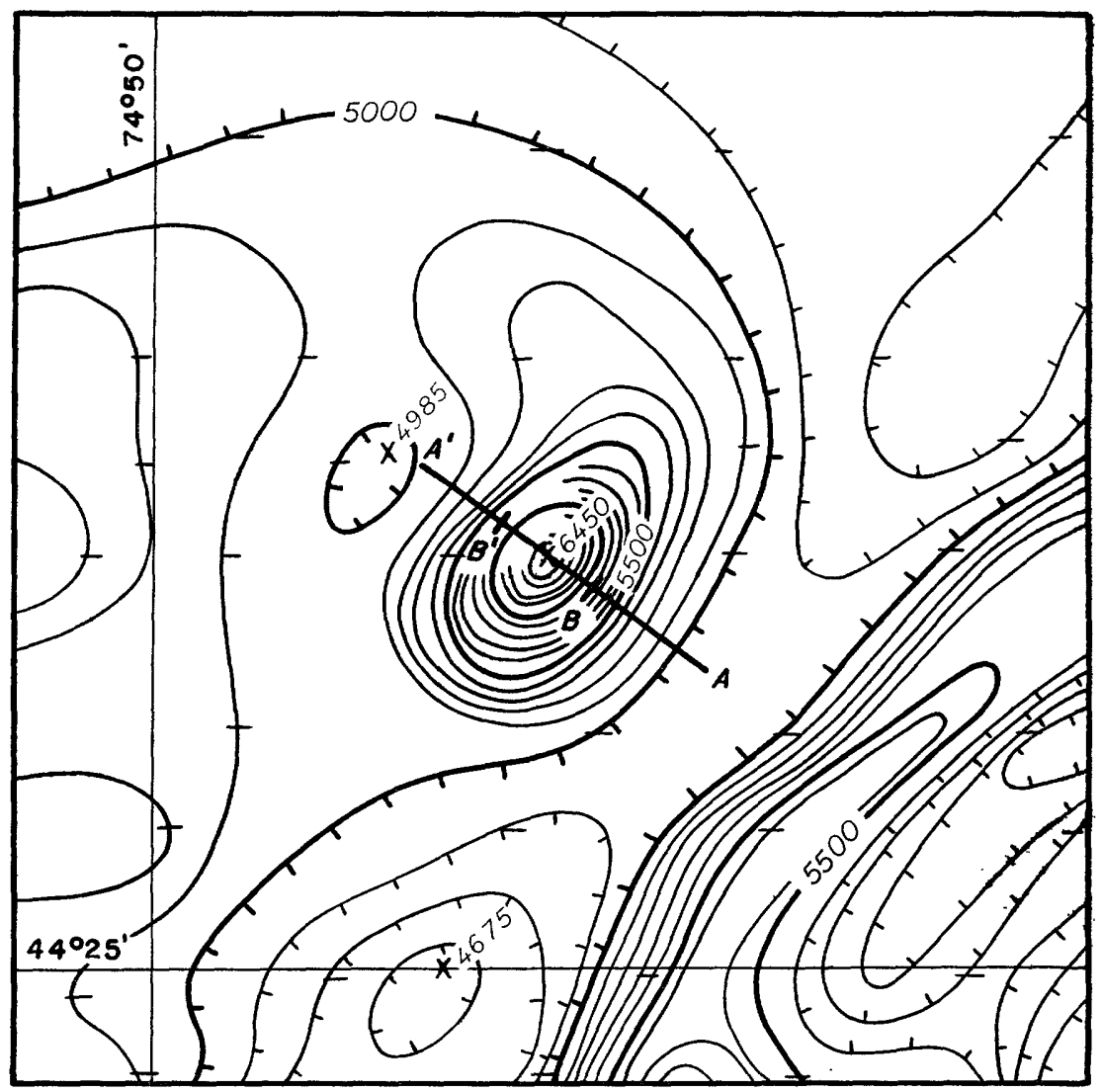

Flown 1000 feet obove surface

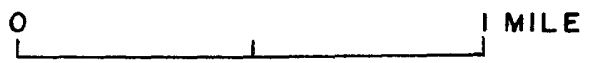

Contour interval 100 gammas

\section{$B-B^{\prime}$ IS HALF-MAXIMUM DISTANCE ON PROFILE $A-A^{\prime}$}

FIGURE 43.-Total-intensity aeromagnetic map of northern part of Stark quadrangle, New York: 


\section{CONCLUSIONS}

The application of magnetic-doublet theory has been shown to be reasonably effective for determinations of the depth of cylindrical laboratory models oriented in the direction of the earth's magnetic field. The determination of doublet length is less reliable. In general the method yields better results for bodies in low magnetic inclinations. The method cannot be expected to give satisfactory values in high magnetic inclinations when the mean radius of a horizontal section exceeds the depth of burial. The most practical use of the method is in depth determinations. The anomaly curves of figures 28 to 34 are also useful qualitatively in obtaining some idea of the anomalies to be expected at various inclinations and the relative displacement of maximums.

\section{LITERATURE CITED}

Alldredge, L. R., and Dichtel, W. J., 1949, Interpretation of Bikini magnetic data: Am. Geophys. Union Trans., v. 30, p. 831-385.

Balsley, J. R., and others, 1954, Total aeromagnetic intensity and geologic map of Stark, Childwold, and part of Russell quadrangles, New York: U. S. Geol. Survey Geophys. Inv. Map GP 117, scale 1 inch=about 1 mile [1955].

Canada Geological Survey [1950], Aeromagnetic map, Campbellford sheet [Ontario] No. 315: Canada Geol. Survey Geophysics Paper 13, scale 1 inch=1 mile.

Deel, S. A., and Howe, H. H., 1948, United States magnetic tables and magnetic charts for 1945: U. S. Coast and Geod. Survey Serial 667, 137 p.

Dempsey, W. J., and Duffner, R. T., 1949, Total intensity aeromagnetic map of Coldwater quadrangle [Madison and Wayne Counties] Missouri: U. S. Geol. Survey Geophys. Inv. Map, scale 1 inch $=1 / 2$ mile.

Dempsey, W. J., Henderson, J. R., and Duffner, R. T., 1949, Total intensity aeromagnetic map of La Porte County, Indiana: U. S. Geol. Survey Geophys. Inv. Map, scale 1 inch $=1$ mile.

Gassman, Fritz, 1951, Graphical evaluation of the anomalies of gravity and of the magnetic field, caused by three-dimensional bodies: 3d World Petroleum Cong., The Hague 1951, Proc., sec., 1, p. 613-621.

Heiland, C. A., 1940, Geophysical exploration: New York, Prentice-Hall Inc., $1013 \mathrm{p}$.

Henderson, J. R., and Meuschke, J. L., 1951, Total intensity aeromagnetic map of Jay County, Indiana: U. S. Geol. Survey Geophys. Inv. Map GP 86, scale 1 inch $=1$ mile.

Henderson, J. R., Jr., and Zietz, Isidore, 1958, Interpretation of an aeromagnetic survey in Indiana: U. S. Geol. Survey Prof. Paper 316-B [in press].

Henderson, R. G., and Zietz, Isidore, 1948, Analysis of total magnetic intensity anomalies produced by point and line sources: Geophysics, v. 13, p. 428-436.

1957, Graphical calculation of total-intensity anomalies of threedimensional bodies: Geophysics, v. 22, p. 887-904. 
Jakosky, J. J., 1950, Exploration geophysics: Los Angeles, Calif., Trija Publishing Co., $1195 \mathrm{p}$.

Nettleton, L. L., 1940, Geophysical prospecting for oil: New York, McGraw-Hill Book Co., 444 p.

Vacquier, Victor, Steenland, N. C., Henderson, R. G., and Zietz, Isidore, 1951, Interpretation of aeromagnetic maps: Geol. Soc. America Mem. 47, $151 \mathrm{p}$.

Vestine, E. H., and Davids, Norman, 1945, Analysis and interpretation of geomagnetic anomalies: Terrestrial Magnetism and Atmospheric Electricity, v. 50, p. 1-36.

Vestine, E. H., Laport, Lucile, Lange, Isabelle, Cooper, Caroline, and Hendrix, W. C., 1947, Description of the earth's main magnetic field and its secular change, 1905-1945: Carnegie Inst. Washington Pub. 578, 532 p.

Zietz, Isidore, and Henderson, R. G., 1956, A preliminary report on model studies of magnetic anomalies of three-dimensional bodies: Geophysics, v. 21, p. 794-814. 


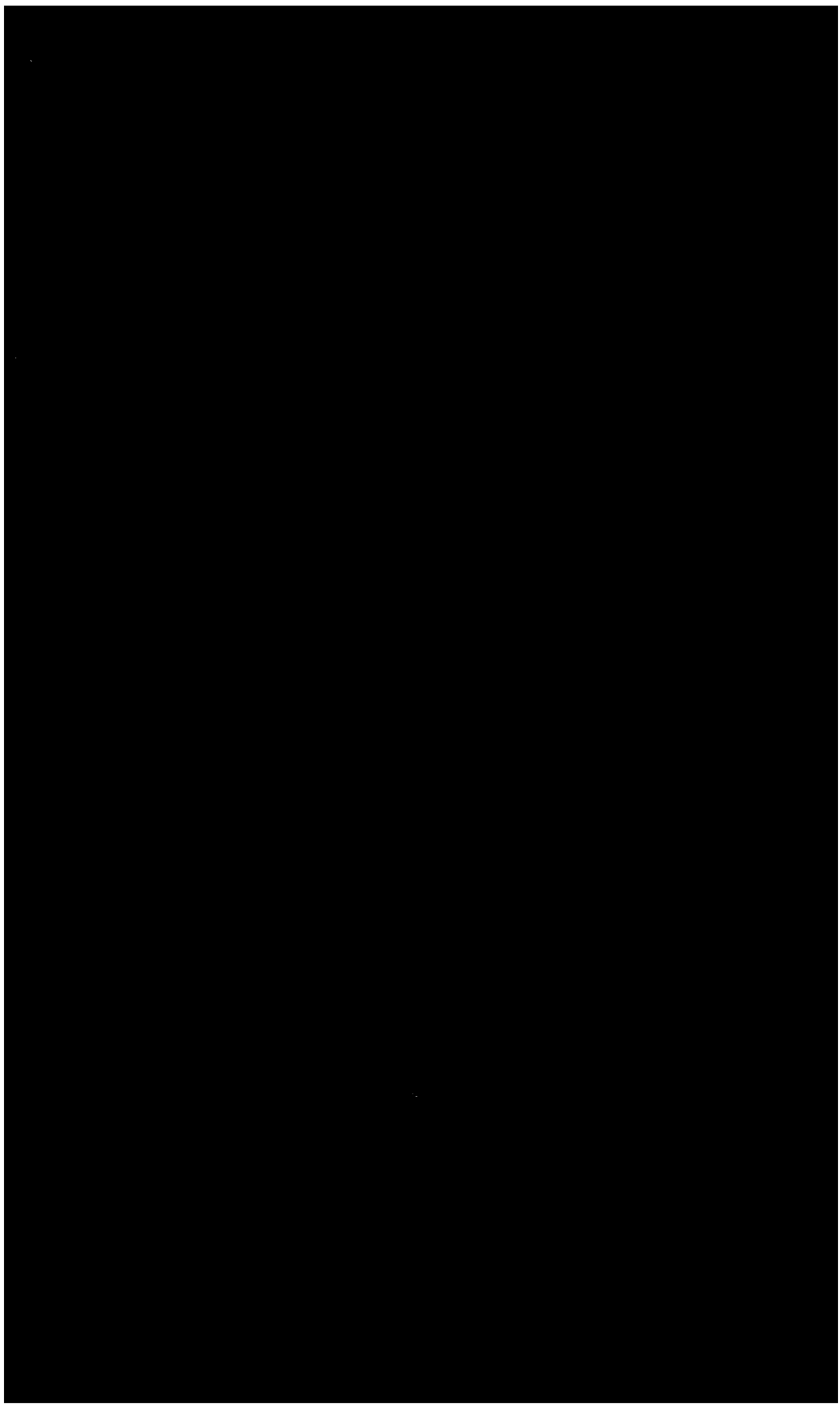




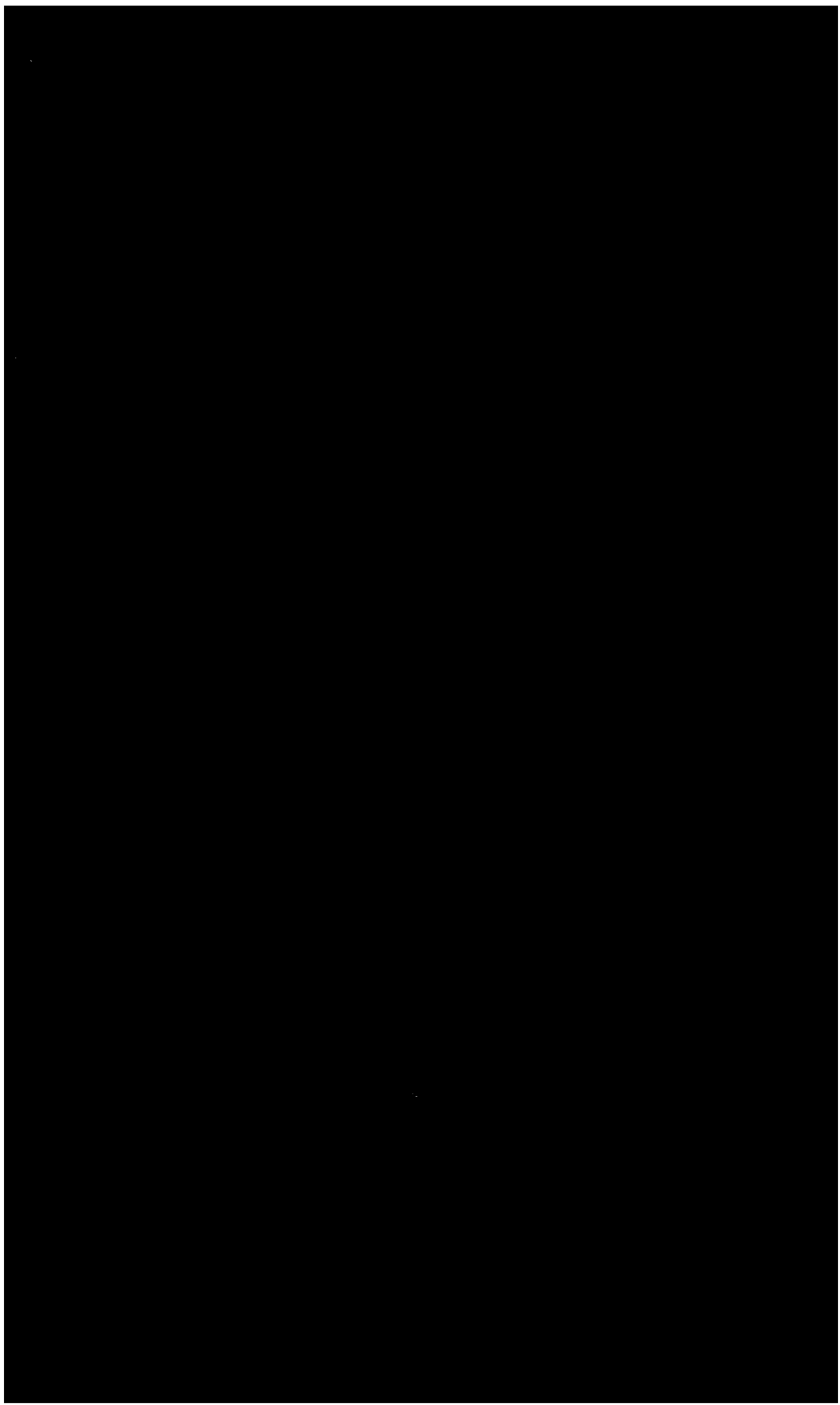

